\title{
Bacillus firmus for the biological control of Meloidogyne hapla and Xiphinema americanum
}

\author{
Lisa M. Valencia
}

Follow this and additional works at: https://researchrepository.wvu.edu/etd

\section{Recommended Citation}

Valencia, Lisa M., "Bacillus firmus for the biological control of Meloidogyne hapla and Xiphinema americanum" (2016). Graduate Theses, Dissertations, and Problem Reports. 6860.

https://researchrepository.wvu.edu/etd/6860

This Thesis is protected by copyright and/or related rights. It has been brought to you by the The Research Repository @ WVU with permission from the rights-holder(s). You are free to use this Thesis in any way that is permitted by the copyright and related rights legislation that applies to your use. For other uses you must obtain permission from the rights-holder(s) directly, unless additional rights are indicated by a Creative Commons license in the record and/ or on the work itself. This Thesis has been accepted for inclusion in WVU Graduate Theses, Dissertations, and Problem Reports collection by an authorized administrator of The Research Repository @ WVU. For more information, please contact researchrepository@mail.wvu.edu. 


\title{
Lisa M. Valencia
}

\begin{abstract}
Thesis submitted to the Davis College of Agriculture, Natural Resources and Design at West Virginia University in partial fulfillment of the requirements for the degree of
\end{abstract}

\author{
Master of Science \\ in \\ Applied and Environmental Microbiology
}

James B. Kotcon, Ph.D., Chair

Alan J. Sexstone, Ph.D.

Gary K. Bissonnette, Ph.D.

Division of Plant and Soil Sciences

\section{Morgantown, WV}

2016

Keywords: Bacillus firmus, Meloidogyne hapla, Xiphinema americanum, plant-parasitic nematode, biological control, bionematicide, mode of action, chemotaxis

Copyright 2016 Lisa M. Valencia 


\title{
ABSTRACT \\ Bacillus firmus for the biological control of Meloidogyne hapla and Xiphinema americanum
}

\begin{abstract}
Lisa M. Valencia
Root-knot nematode (RKN) and dagger nematode (DN) are serious pests of agricultural crops, including peach trees of West Virginia. RKN is a sedentary endoparasite that feeds and reproduces within the roots of host plants, causing gall formation, loss of vigor, and plant death. $\mathrm{DN}$ is an ectoparasite that has the potential to vector devastating plant viruses. Many control options recommended for annual crops are not appropriate for orchards and the use of chemical nematicides is limited. The endospore-forming bacterium, Bacillus firmus (BF), is marketed as a bionematicide, though its mode of action and efficacy in controlling certain nematodes indigenous to West Virginia are unclear. The purpose of this study was to determine efficacy and mode of action of BF as a bionematicide against the northern RKN, Meloidogyne hapla and DN, Xiphinema americanum. Direct toxicity was determined by exposing RKN and DN to various concentrations of BF over a 72-hour period. Exposure to a $10^{7} \mathrm{CFU} / \mathrm{ml}$ concentration of BF caused a $15 \%$ decrease in living RKN and an $11 \%$ decrease in living DN by 72 hours. No effect was observed with lower concentrations. In-vitro attraction assays were performed to determine if the presence of BF affects nematode migration and infection rates. Filter paper discs were treated with $\mathrm{BF}$ and sterile soil extract (SSE) and were placed at either end of a slide covered with Pluronic gel. Approximately $150 \mathrm{RKN}$ or $30-50 \mathrm{DN}$ were placed in the center of each slide and the number of nematodes that left the center and migrated to each side was counted at 1, 2, 4, and 24 hours post inoculation. A similar attraction assay was performed with tomato seedlings instead of filter paper. Filter paper assays showed that $93 \%$ of motile RKN were observed on the SSE portion of the slides compared to $7 \%$ on the BF side by hour 24 . Attraction assays using tomato seedlings showed $71 \%$ of motile RKN were observed on the portion of slides with SSEtreated roots, compared to $29 \%$ on the side with BF-treated roots. DN results were contrary to RKN results. Filter paper assays showed $59 \%$ of motile DN on the BF portion of slides compared to $41 \%$ on the SSE side, while tomato seedling assays showed no significant difference between treatments at hour 24. Infection assays using seedlings on glass slides showed an average of three RKN successfully penetrated BF-treated roots compared to 20 in SSE roots. Attraction assays in sand, comparing RKN infection of BF and SSE-treated tomato seedlings, showed no significant difference between treatments. Nematode mortality observed after exposure to BF suggests that BF produces secondary metabolites that are directly toxic to RKN and $\mathrm{DN}$, though these metabolites have limited potency. Behavior of RKN in the presence of BF suggests the involvement of a chemorepellent, while the behavior of DN suggests the involvement of a chemoattractant. The results of this study indicate that the mode of action of BF is linked to the production of chemorepellent compounds, though these chemotactic factors are species specific. BF is a promising biocontrol option for the management of RKN but may not demonstrate the same measure of control against DN.
\end{abstract}




\section{Dedication}

To the many amazing people that helped make this happen and kept me sane through the process. A very special thanks to NAKS, mom, and my Baby Bugg. 


\section{Acknowledgements}

This work was supported in part by the West Virginia Department of Agriculture Specialty Crop Block Grant Program, Grant Agreement \#2014SC13. Bayer CropScience contributed a sample of Bacillus firmus strain I-1582. Shanholtz Orchard, Romney, West Virginia, contributed soil from which $X$. americanum was isolated. The authors wish to thank Ida Holaskova at West Virginia University for assistance with statistical analyses; the Kasson lab, specifically Angie Macias, for help in DNA extraction and gene sequencing; and Ember Morrissey for help navigating the NCBI database. 


\section{TABLE OF CONTENTS}

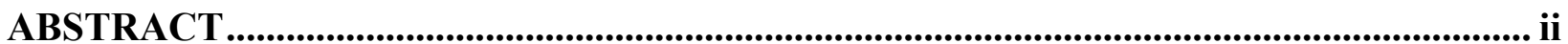

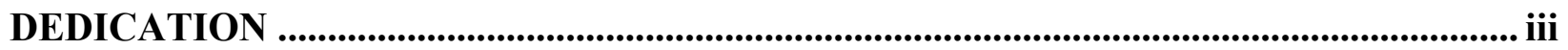

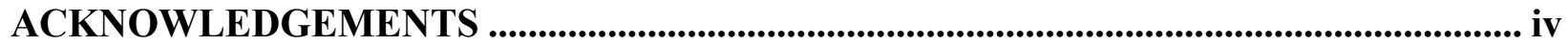

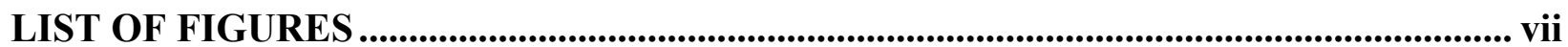

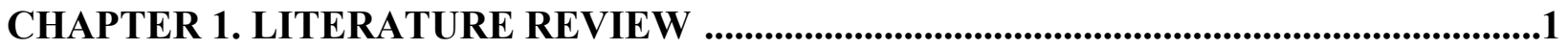

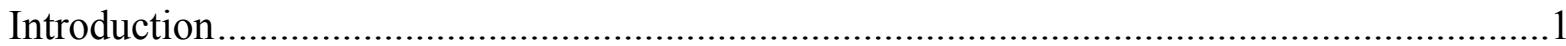

Plant-parasitic nematodes ............................................................................................

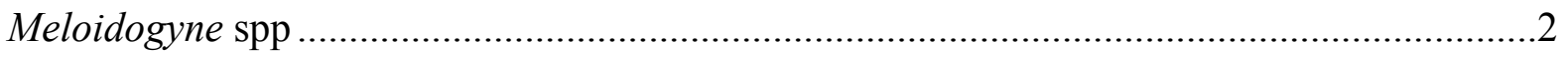

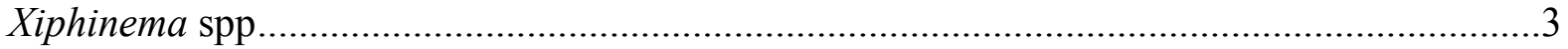

Nematode management.................................................................................................

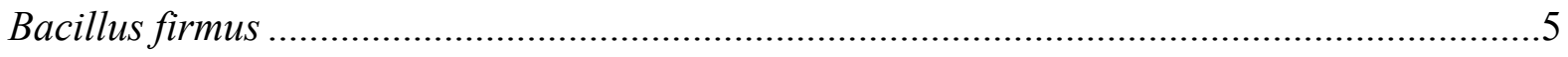

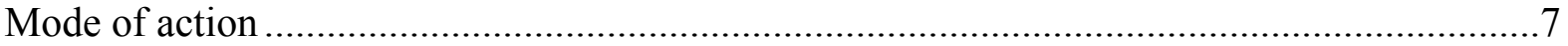

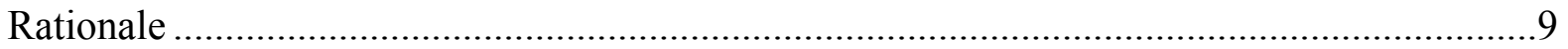

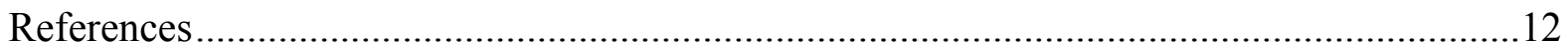

CHAPTER 2. EFFICACY AND MODE OF ACTION OF BACILLUS FIRMUS AS A

BIONEMATICIDE FOR THE NORTHERN ROOT-KNOT NEMATODE,

MELOIDOGYNE HAPLA ........................................................................................................19

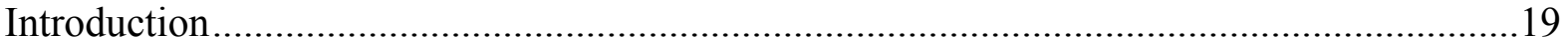

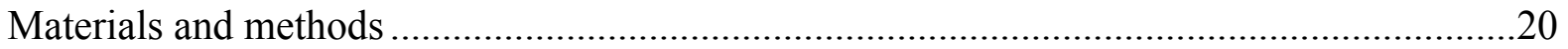

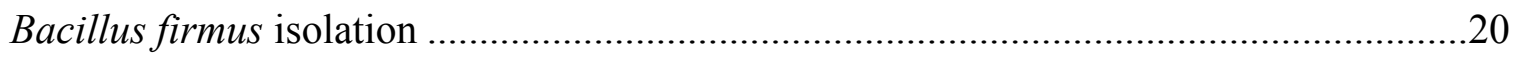

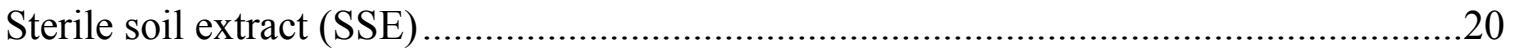

Meloidogyne hapla ..............................................................................................21

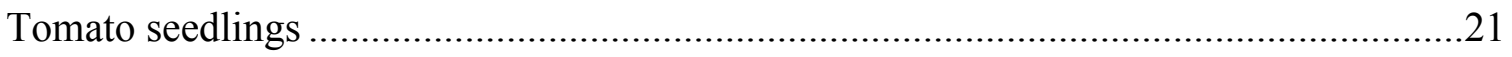

Experiment 1: Bacillus firmus direct toxicity assay .....................................................21

Experiment 2: Filter paper attraction assay .................................................................22

Experiment 3: Tomato seedling attraction assay …………….....................................22

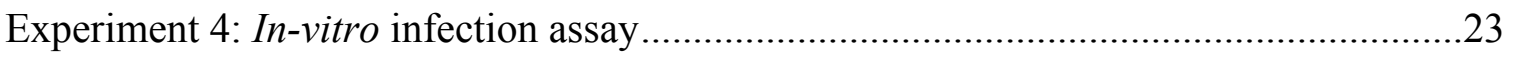

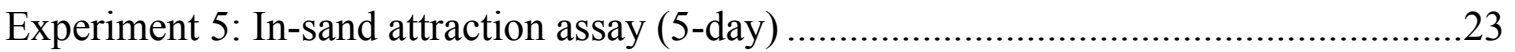

Experiment 6: In-sand reproduction assay (40-day) ........................................................24 


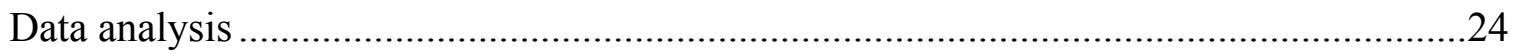

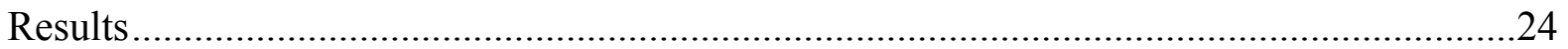

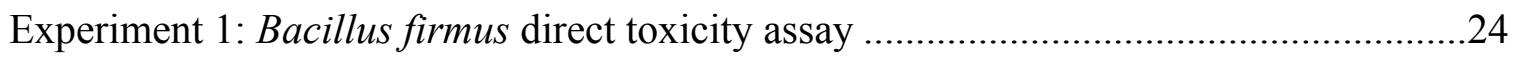

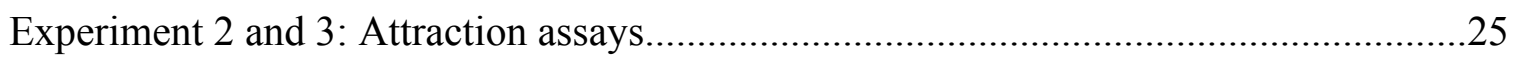

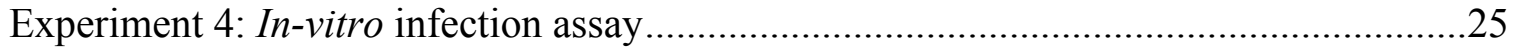

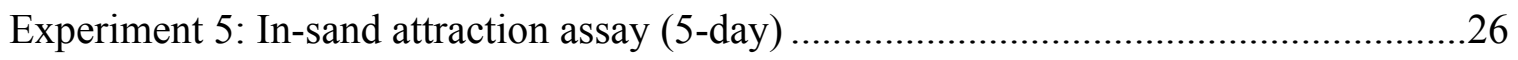

Experiment 6: In-sand reproduction assay (40 day) .................................................26

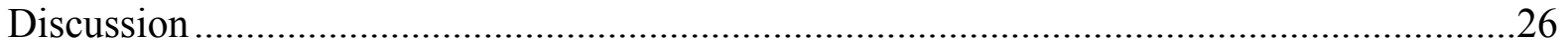

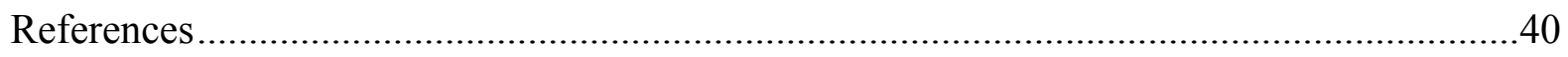

\section{CHAPTER 3. EFFICACY OF BACILLUS FIRMUS AS A BIONEMATICIDE AGAINST}

XIPHINEMA AMERICANUM ...........................................................................................43

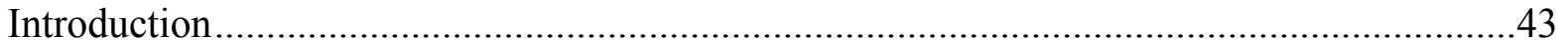

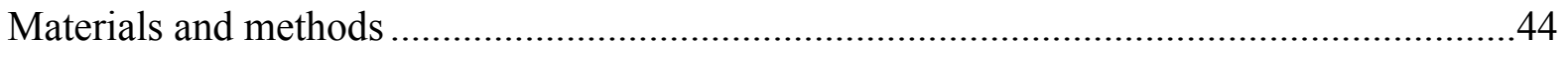

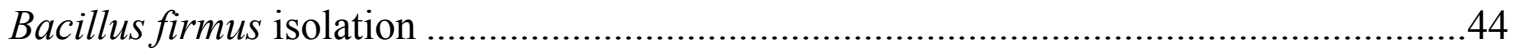

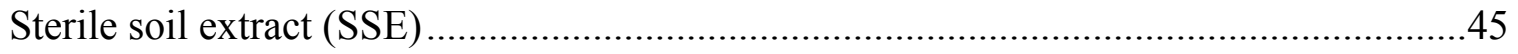

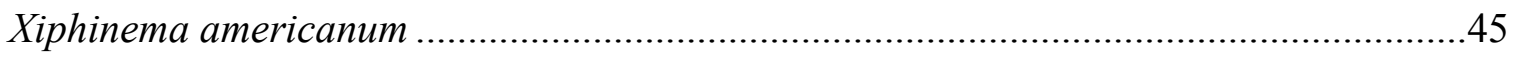

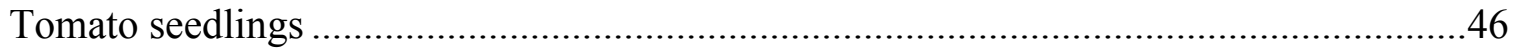

Experiment 1: Bacillus firmus direct toxicity assay ...................................................46

Experiment 2: Filter paper attraction assay ........................................................ 46

Experiment 3: Tomato seedling attraction assay ................................................... 47

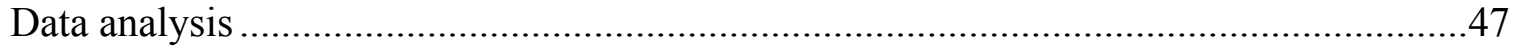

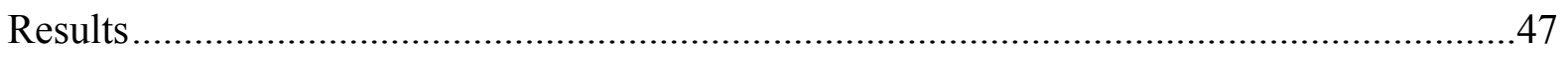

Experiment 1: Bacillus firmus direct toxicity assay ................................................48

Experiment 2: Filter paper attraction assays ........................................................ 48

Experiment 3: Tomato seedling attraction assay ................................................. 48

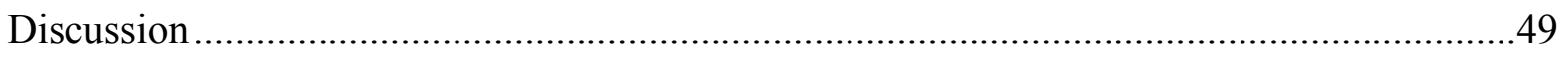

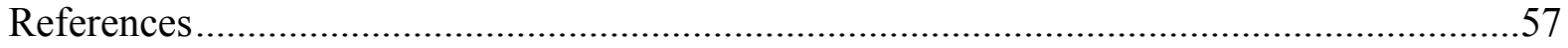

Appendix 1 ........................................................................................................................................60

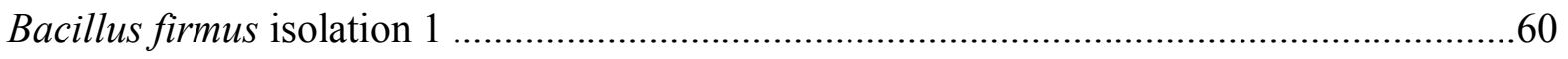

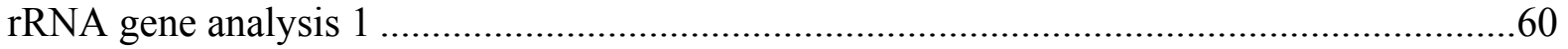

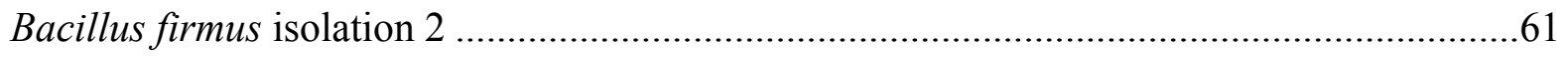




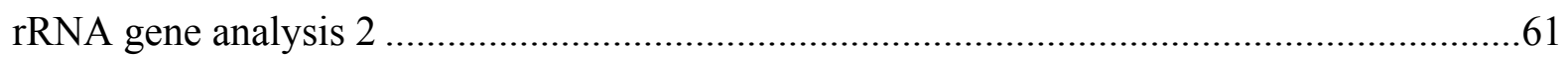




\section{LIST OF FIGURES}

Chapter 2 - Figure 2.1. In-vitro attraction assay set-up: B. firmus- and SSE-treated filter paper on opposite ends of slides covered in Pluronic gel

Chapter 2 - Figure 2.2. In-pot attraction assay set-up: Beakers containing both B. firmusand SSE-treated tomato seedlings on opposite sides

Chapter 2 - Figure 2.3. Direct toxicity assay: Proportion of living $M$. hapla nematodes after 24, 48, and 72 hours of exposure to different concentrations of B. firmus. Error bars represent standard error of the mean

Chapter 2 - Figure 2.4. Filter paper attraction assay: Number of $M$. hapla nematodes observed on the B. firmus portion of the slide vs. the SSE portion of the slide over time. The shaded regions represent confidence intervals of the slope.

Chapter 2 - Figure 2.5. Tomato seedling attraction assay: Number of $M$. hapla nematodes observed on the B. firmus portion of the slide vs. the SSE portion of the slide over time. The shaded regions represent confidence intervals of the slope

Chapter 2 - Figure 2.6. In-vitro infection assay: The average number of M. hapla nematodes that successfully penetrated roots of $B$. firmus-treated tomato seedlings vs. SSEtreated tomato seedlings. Error bars represent standard error of the means

Chapter 2 - Figure 2.7. In-sand attraction assay (5-day): The average number of $M$. hapla nematodes that successfully penetrated roots of $B$. firmus-treated tomato seedlings vs. SSEtreated tomato seedlings. Error bars represent standard error of the means.

Chapter 2 - Figure 2.8. In-sand reproduction assay (40-day): The average number of reproductive $M$. hapla females within the roots of $B$. firmus-treated tomato seedlings vs. SSE-treated tomato seedlings. Error bars represent standard error of the means. .38 
Chapter 2 - Figure 2.9. In-sand reproduction assay (40-day): The average number of eggs per reproductive $M$. hapla female within the roots of $B$. firmus-treated tomato seedlings vs. SSE-treated tomato seedlings. Error bars represent standard error of the means

Chapter 3 - Figure 3.1. In-vitro attraction assay set-up: B. firmus- and SSE-treated filter paper on opposite ends of slides covered in Pluronic gel

Chapter 3 - Figure 3.2. Direct toxicity assay: Proportion of living $X$. americanum nematodes after 24, 48, and 72 hours of exposure to different concentrations of B. firmus. Error bars represent standard error of the mean.

Chapter 3 - Figure 3.3. Filter paper attraction assay: Number of $X$. americanum nematodes observed on the $B$. firmus portion of the slide vs. the SSE portion of the slide over time. The shaded regions represent confidence intervals of the slope.

Chapter 3 - Figure 3.4. Tomato seedling attraction assay: Number of $X$. americanum nematodes observed on the B. firmus portion of the slide vs. the SSE portion of the slide over time. The shaded regions represent confidence intervals of the slope. 


\section{CHAPTER 1}

\section{LITERATURE REVIEW}

Introduction

Plant-parasitic nematodes are serious pests of agriculture that continue to threaten the security of the commercial fruit industry in West Virginia and other Mid-Atlantic states (Kotcon, 1990; Walters and Barker, 1994; Koenning et al., 1999). Many of the nematode species that parasitize plants, most notably species of Meloidogyne, cause major crop losses throughout the world. The damage generated by the parasitic activity of these nematodes can be further amplified by the ability of certain species, including Xiphinema spp., to act as virus vectors. As the available chemical options for nematode management decline, growers diagnosed with nematode problems have limited options, many of which are unacceptable for established orchard sites. These situations call for effective bionematicide alternatives. Several studies have demonstrated that the bacterium Bacillus firmus is an effective option for biological control of certain nematode species. However, it is uncertain if this organism maintains similar efficacy against problematic nematodes of West Virginia fruit trees such as Meloidogyne hapla and Xiphinema americanum. Furthermore, the specific nematicidal mode of action employed by $B$. firmus remains disputed.

\section{Plant-parasitic nematodes}

Plant-parasitic nematodes are economically important agricultural pests, causing billions of dollars in crop damage annually (Handoo, 1998). As these microscopic roundworms feed on the roots of plants, they impair the health and vigor of crops, which can result in an overall decline in crop yields as well as host plant death. A 1994 survey of various crops grown in 35 states of the USA indicated that at least $25 \%$ of crop losses can be attributed to the presence of plant-parasitic nematodes (Koenning et al., 1999). This plant damage may be a direct result of nematode infection within roots and ingestion of cell contents, or may be associated with indirect consequences of nematode parasitic activity. Nematode-inflicted wounds on root tissue leave plants more susceptible to secondary infection by fungal and bacterial pathogens, and may also facilitate transmission of nematode-vectored plant viruses (Powell et al., 1971; Brown et al., 1995). Two of the most economically important nematode genera, Meloidogyne spp. and Xiphinema spp., are abundant in peach and apple orchards of West Virginia (Kotcon, 1990). 


\section{Meloidogyne spp.}

Root-knot nematodes of the genus Meloidogyne are regarded as highly destructive pests to agricultural crops worldwide (Barbosa et al., 2004; Gugino et al., 2006; Hussain et al., 2011; Koenning et al., 1999; Wesemael et al., 2011). These sedentary endoparasites live most of their lives within the roots of their host plants, feeding on cytoplasmic material of root cells. Female root-knot nematodes use both sexual and asexual reproduction, laying upwards of 1000 eggs while embedded within the host plant roots (Chitwood and Perry, 2009). After completing embryogenesis and one molt, the larvae emerge from their eggs as second stage juveniles (J2), the infectious stage of the species, and either re-infect the same root or migrate to new infection sites. $\mathrm{CO}_{2}$ and other volatile compounds associated with plant roots act as chemoattractants to the J2s, allowing them to orient themselves accordingly to find host plant roots (Robinson, 1995; Wang et al., 2009). Once an acceptable host root has been located, the nematode secretes degrading enzymes and uses its stylet to puncture the root tissue near the zone of elongation, and migrates inside (Wyss et al., 1992). The nematode quickly establishes a feeding site where it remains sedentary through the remainder of its life, if female, or until it molts into a mature adult, if male. Salivary secretions produced by the nematode promote the formation of several multinucleated giant cells that act as nutrient pools for the feeding nematode (Bird, 1962; Jones, 1981; Mor (Mordechai) and Oka, 2006). Root galls form around the area of infection, which ultimately inhibits the flow of water and nutrient within host plant roots.

The life cycle of root-knot nematodes is temperature dependent and is completed in approximately 600 degree days with a base temperature of $8.13^{\circ} \mathrm{C}$ (Bird and Wallace, 1965; Vrain et al., 1978; Starr and Mai, 1976; Lahtinen et al., 1988). Within host plant roots, J2s undergo three additional molts to develop into a mature, reproductive adult. Adult males are vermiform and mobile. Adult females are pyriform and sedentary, maintaining only the musculature in the neck region to enable feeding (Eisenback and Hunt, 2009). Each reproductive female deposits several hundred eggs on the surface of host plant roots, held together within a gelatinous matrix. The ability of these nematodes to produce large numbers of progeny in short periods of time can quickly overwhelm susceptible agricultural crops. If root-knot nematode infestations are left untreated, plants can exhibit signs of severe nutrient deficiencies such as stunting, yield loss, and death. If numbers are maintained at population levels below the damage 
threshold, root-knot nematodes are considered less of an immediate threat to West Virginia peach and apple orchards, however, once they become established in these deep-rooted perennial crops, control is difficult and options are limited (Nyczepir, 1991).

\section{Xiphinema spp.}

Dagger nematodes are migratory ectoparasites belonging to the Longidoridae family. The female worms produce eggs by parthenogenesis and observation of males is rare. In contrast with many nematode species, Xiphinema spp. maintains a relatively low reproductive rate and a long lifespan. Their life cycle may take several months to over a year to complete and they have been reported to live 2-5 years in their natural soil environments, laying only a few eggs monthly (Flegg, 1968; Cohn and Mordechai, 1969; Brown and Coiro; 1983; Brown, 1986). These nematodes live their entire lives within the soil and feed along the growing roots of plants with a long, needle-like stylet (Cohn, 1970; Weischer and Wyss, 1976). The stylet punctures through plant cell walls, enabling the nematode to ingest the cytoplasmic material of cells. It is this method of ectoparasitism, along with their long life span, wide host range, and persistence in fallow soil that contribute to the efficiency of Xiphinema spp. as a vector of nepoviruses.

Dagger nematodes are notorious virus vectors that are known to transmit viruses within the genus Nepovirus (nematode transmitted polyhedral viruses) throughout a wide range of host plants (Brown et al., 1993; Taylor and Raski, 1964). One such virus, tomato ringspot virus (TomRSV), is the causal agent of peach stem pitting (PSP), a devastating affliction of peach trees, and apple union necrosis and decline (AUND) in apple trees (Smith et al., 1973; Parish and Converse, 1981). PSP-diseased trees possess highly disorganized xylem tissue which can enable the breakage of whole trees in just a few years (Barrat et al., 1968). AUND produces similar symptoms within apple trees, though typically less severe than those observed in peach and generally confined to the graft union (Stouffer et al., 1977). TomRSV infections cannot be cured and diseased trees must be removed and destroyed to prevent viral spread, a practice that often leads to great losses within a single orchard. Dagger nematodes responsible for transmission of TomRSV are a persistent presence in Mid-Atlantic orchards (Georgi, 1988; Jaffee et al., 1987). Kotcon (1990) determined that at least $74 \%$ of peach orchards surveyed in West Virginia harbor Xiphinema spp., and it can be expected that apple orchards maintain similar Xiphinema spp. populations. 
As dagger nematodes feed on infected plants, viral particles may adhere to the stylet and esophageal lumen of the feeding nematode, establishing the nematode as a potential virus vector (Taylor and Robertson, 1970; Raski et al, 1973). Viral particles will remain attached until the nematode molts or the stylet is used to puncture root tissue of a new host plant. During feeding, dagger nematodes secrete digestive enzymes into the cytoplasm of root cells, a process that can cause attached viral particles to dislodge and be transmitted directly into the new host cell (Taylor and Robertson, 1970). The virus is then free to replicate and eventually translocate throughout the plant. These viral particles can be acquired by subsequent nematode feeding, allowing the cycle of transmission to continue. The potential for dagger nematodes to act as virus vectors complicates the issue of nematode damage thresholds. Plants parasitized by virus-free dagger nematodes show few symptoms at low to moderate nematode population densities. However, nematodes harboring viral particles can fuel the development of serious crop damage. A single dagger nematode can transfer TomRSV to a susceptible host plant, and only a few are

needed to infect multiple new host plants in a matter of weeks (Mountain et al., 1992). Plants are rarely infected with TomRSV mechanically, leaving dagger nematodes as the primary mode of viral transmission. Elimination of the nematode vector is crucial for controlling the frequency of disease.

Nematode management

Traditional means of nematode management, such as crop rotation, are not always appropriate or cost effective for orchard sites. Resistant rootstocks are recommended, however, the use of rootstocks, as well as rootstock selection is based heavily on individual orchard situations (Esmenjaud et al., 1994; Fernández et al, 1994; McKenry et al., 2001). Not all cultivars are compatible with resistant rootstocks and different rootstocks offer varied resistance to nematode species, as well as other plant pathogens (Nyczepir, 1991). With the escalated concern for human and environmental safety, the ability to manage nematode populations with classic chemical nematicides is waning. Few options are available to peach and apple growers, and recommendations often involve removal of whole trees and fumigation of fallow land.

Except for the insecticide spirotetramat, there are presently no chemical nematicides registered for application on bearing fruit trees in the state of West Virginia. There remains a clear need for novel biological control options that offer reliable control of nematodes within orchard settings, 
while remaining environmentally benign. As it stands today, a limited number of commercialized bionematicides reporting efficacy in nematode control are available for use in various agricultural systems. Notable biological agents used as active ingredients within these products include Pasteuria spp., Purpureocillium lilacinum, and Bacillus firmus (Kariuki et al., 2006; Singh et al; 2013; Keren-Zur et al., 2000). In recent years, the most successful bionematicide, based on consumer reports, has been the Bayer CropScience product, VOTiVO, a seed treatment utilizing the bacterium B. firmus (Wilson and Jackson, 2013).

\section{Bacillus firmus}

Bacillus firmus is a member of the genus Bacillus, a diverse group of gram-positive, endospore-forming bacteria. Along with the anaerobic group of Clostridia, these aerobic or facultative anaerobic organisms make up a large part of the Firmicutes phylum. Species within the genus Bacillus are ubiquitous in nature. A large majority of Bacillus spp. are soil-dwelling saprophytes, though a few species are known to have medical, agricultural, and industrial significance (Turnbull, 1996). B. anthracis and, occasionally, B. cereus are pathogenic to humans and other animals, $B$. thuringiensis-produced crystals are used as a bioinsecticide in agriculture, and certain Bacillus species are employed in the industrial production of useful organic compounds such as vitamins and proteins (Welkos et al., 1986; Pezard et al., 1991; Bottone, 2010; Höfte and Whiteley, 1989; Tang et al., 2004; Bajaj and Manhas, 2012). Bacillus spp. have a diverse range of physiological characteristics that allow them to inhabit a variety of ecological niches, including those with environmental extremes of high temperature, high $\mathrm{pH}$, and high salt (Epstein and Grossowicz, 1969; Nielsen et al., 1995; Ventosa et al., 1989; Turnbull, 1996). Their endospore-forming capabilities allow them to survive unsuitable conditions for hundreds, if not millions, of years (Cano and Borucki, 1995; Errington, 2003). High bacterial densities and limited nutrient availability trigger sporulation of Bacillus spp., with each vegetative cell producing one dormant endospore capable of surviving UV radiation, extreme desiccation, dry and wet heat, and common disinfectants (Sonenshein, 2000; Nicholson et al., 2000). When endospores sense the return of favorable conditions, they germinate back to their vegetative form.

Because of the diversity of these organisms and the unique characteristics associated with

them, Bacillus spp. have been subject to a great deal of research in the past several decades. They possess unique qualities that make them desirable for the biological control of nuisance 
organisms such as pathogenic bacteria and plant-parasitic nematodes, and their endospore survival strategy allows them to persist over time within desiccated soil, a feature that may be exploited for convenient packaging and distribution as pesticides. Bacillus spp. produce an array of secondary metabolites that perform a variety of biological functions, including antagonistic activities on neighboring microorganisms and the promotion of symbiotic relationships within the rhizosphere (Sansinenea and Ortiz, 2001; Chen et al., 2008; Leelasuphakul et al., 2008). B. subtilis, for example, is able to produce over two dozen antibiotics of medical and agricultural significance, and devotes nearly $5 \%$ of its genome to the cause (Stein, 2005). B. thuringiensis produces crystals during sporulation that have insecticidal properties, a trait that has been applied to the genetic modification of agricultural crops (Schnepf et al., 1998). Wei et al. (2003) revealed that the toxicity of these proteins extends to the phylum Nematoda. The relatively new discovery of a nematicidal strain of $B$. firmus (I-1582) has prompted numerous investigations into the use of this organism to suppress agriculturally destructive nematode populations (Peleg and Feldman, 1996).

The nematicidal strain of B. firmus (I-1582) was first isolated from cultivated soils of Israel, quickly becoming the active biological agent of a novel bionematicide, BioNem-WP. Under laboratory conditions, Keren-Zur et al. (2000) demonstrated that applications of the $B$. firmus-based product to Meloidogyne javanica-infested soil caused a rapid decline in juvenile viability within a period of 3 to 5 days, and further maintained low root-knot nematode densities of less than 1 juvenile per gram of soil throughout the remainder of the experiment's 20-day period. Field trials incorporating $B$. firmus into root-knot infested sandy soils subsequently planted with tomato seedlings demonstrated that the product reduced the galling index of roots from 4-5 (an index representing severe galling) in the untreated controls, down to an index of 1-2 (an index representing mild galling), for 50 and 85 days after planting. This novel research provided strong evidence that the use of Bacillus firmus-based nematicides for agricultural purposes was worth further investigation.

Giannakou et al. (2003) used greenhouses infested with Meloidogyne spp. to compare the efficacy of BioNem-WP in controlling root-knot infection of cucumber plants to standard fumigant and nonfumigant nematicides and the well-known biocontrol agent Pasteuria penetrans. The study demonstrated that, though B. firmus was less effective as a nematicide than 1,3-dichloropropene, dazomet, and oxamyl, nematode populations were significantly lowered 
with band applications of $B$. firmus compared with the untreated control, and even further reduced with broadcast applications. The study also showed that B. firmus was more effective at reducing root-knot nematode populations than $P$. penetrans and could suppress nematode population densities throughout the growing season, an aspect that can drastically reduce nematicide application costs for growers. Through a series of in-vitro and greenhouse trials, Terefe et al. (2009) presented compelling evidence that BioNem-WP was successful in controlling root-knot populations. Applications of BioNem-WP in concentrations varying from 0.5 to $2.5 \%$ (Bionem concentrations produced by adding $0.5,1,1.5,2$, and 2.5 grams of BionemWP powder formulation to $99.5,99,98.5,98$, and $97.5 \mathrm{~mL}$ of sterile water respectively) on Meloidogyne incognita egg masses in-vitro, inhibited egg hatching 98-100\% by 3 days after treatment, while hatching in the control continued up to day 24. Applications of $2.5-3.0 \%$ BioNem-WP to root knot juveniles in-vitro, resulted in 100\% inhibition of motility. BioNem-WP applied to tomato seedlings planted in sterilized soil reduced gall formation up to $91 \%$ and increased plant height and biomass. Mendoza and Sikora (2009) considered the efficacy of $B$. firmus alone and in conjunction with Fusarium oxysporum as a means of controlling Radopholus similis in banana production. They determined that B. firmus significantly reduced $R$. similis penetration into banana roots, while the combination of $B$. firmus and $F$. oxysporum produced a synergistic effect to lower nematode populations as well as increase shoot fresh weight greater than that of the untreated control.

\section{Mode of action}

Though products utilizing Bacillus firmus as an active ingredient have been found effective at reducing nematode densities in the aforementioned studies, conflicting information exists about the biology, ecology, and mode of action of $B$. firmus when used as a nematicide (Wilson and Jackson, 2013). Bionematicidal agents typically offer control of nematode populations by expressing direct toxicity, initiating plant host defense, or interfering with nematode-host interactions. From early studies of the nematicidal strain of $B$. firmus, it was proposed that the organism's mode of action involves the production of toxic secondary metabolites. The BioNem-WP patent application filed April 16, 1996 stated that “...proteolytic and collagenolytic activities play an important role in control of nematodes, either by direct effect on the cuticle of nematode, or indirectly by increasing the release of ammonia which is 
known to be toxic to nematodes due to protein breakdown..." (Patent US6406690, Peleg and Feldman, 1996). The study illustrated that higher levels of proteolytic and collagenolytic activity were expressed by B. firmus compared to other bacterial species examined. It is well established that many species within the genus Bacillus are able to produce various metabolites and extracellular enzymes that have a range of antimicrobial properties. Certain strains of B. firmus have been shown to generate antibiotics that are lethal to other bacteria such as Escherichia coli and species of Staphylococcus (Adamu et al., 2009). This antibiotic production may explain the organism's ability to suppress nematode densities. Mendoza et al. (2008) demonstrated the production of nematicidal bioactive metabolites by $B$. firmus in in-vitro tests on mobile stages of R. similis, M. incognita, and Ditylenchus dipsaci nematodes. Three-day-old cultures of $B$. firmus grown in trypticase soy broth (TSB) were centrifuged to separate bacterial cells from TSB and the supernatant was passed through 0.45 and $0.22-\mu \mathrm{m}$ Millipore filters to remove any remaining cells. Observable paralysis and mortality were seen after root-knot, stem, and burrowing nematodes were incubated in 15-100\% concentrations of bacteria-free culture filtrates. Culture filtrates at $100 \%$ concentration led to 25,33 , and $11 \%$ mortality of R. similis, M. incognita, and D. dipsaci, respectively. Suspensions consisting of $100 \%$ concentrations of bacteria-free culture filtrates applied to M. incognita egg masses resulted in significantly reduced hatching compared with the untreated control. Nematode mortality and hatching inhibition in the absence of bacterial cells demonstrates that $B$. firmus production of bioactive compounds is directly toxic to nematodes.

Bacillus firmus is currently marketed by Bayer CropScience and sold as a nematicide seed treatment (VOTiVO). The proposed mode of action associated with the B. firmus in these products involves bacterial colonization of young roots that create a "living barrier" to promote healthy root growth and reduce nematode damage. It is reported that $B$. firmus competes with nematodes for space along the root system and interferes with nematode host finding ability by consuming plant root exudates. Chemotaxis is an important factor in nematode host finding that involves the interaction of chemotactic signals with cephalic amphids of the nematode. Chemotactic factors accumulate at receptor sites within the amphids and lead to the orientation of the nematode either towards the source of a chemoattractant or away from the source of a chemorepellent (Zuckerman and Jansson, 1984). As nematodes encounter attractive root exudates within their environment, they are drawn towards the suitable host plant's roots. 
Altering these chemical signals can prevent nematodes from finding food or even repel nematodes from their food source.

The relationship between rhizobacteria and plant roots is known to have a variety of positive effects on root development, such as boosting host plant defenses, promoting plant growth, and altering plant root exudates, all of which are a potential hindrance to nematode parasitic behavior (Sikora et al, 2007). Diaz et al. (2009) demonstrated that inoculating roots of Eucalyptus globulus with naturally associated rhizobacteria can stimulate plant rooting, fibrosity and, biomass. The study showed that inoculating soil with various strains of rhizobacteria successfully increased E. globulus plant growth compared to untreated controls. A strain of $B$. firmus specifically isolated from the study, increased rooting by $43.8 \%$. Thus, the application of B. firmus (I-1582) to plants may prove to be a beneficial approach to promoting plant growth as well. Dadwal and Jamaluddin (2010) demonstrated the ability to suppress the occurrence of post emergence root rot of four forest species. A 150-cc aliquot of an 11-day old B. firmus culture (diluted 10 times with sterilized water) was applied to soils inoculated with a pathogenic Fusarium oxysporum spore suspension $\left(10^{6}\right.$ spores $\left./ \mathrm{mL}\right)$ and planted with Acacia nilotica, Albizia procero, Albizia lebbek, and Dalbergia sissoo seedlings. After a 30-day period, seedlings treated with B. firmus showed no evidence of root rot while $13-28 \%$ of the untreated seedlings showed signs of infection. The study demonstrates that $B$. firmus's association with plant roots can have an antagonistic effect on plant pathogenic organisms, an effect that may extend to plant-parasitic nematodes.

\section{$\underline{\text { Rationale }}$}

Control of plant-parasitic nematodes in agricultural systems has proven to be an increasingly daunting task, further complicated by government restrictions on available chemical nematicides as well as the unreliability of available biological controls. Many growers, especially those involved in organic crop and tree fruit production, are left with little insight into how to manage problematic nematodes infestations. Presently, nematicide research aims largely at exploiting the nematicidal properties of soil-dwelling bacteria and fungi to produce environmentally friendly bionematicide options. Bionematicide products utilizing $B$. firmus as the active ingredient have appealed to growers in recent years, yet information regarding the bacterium's ability to control different nematode species is limited. Research has focused, to a 
large extent, on the effects of $B$. firmus applications on root-knot nematodes, namely $M$.

incognita and M. javanica. Several studies have demonstrated the superior ability of B. firmus to suppress nematode motility, egg hatching, root penetration, and galling on a variety of host plants, though the organism's specific nematicidal mode of action remains disputed (Giannakou et al., 2003; Mendoza et al., 2008; Castillo et al., 2013; Crow, 2014). Understanding the direct consequences of B. firmus applications on nematode infested soils will confirm the value of this novel bionematicide for nematode control.

With the ability to transmit viruses such as TomRSV, dagger nematodes pose a huge threat to the commercial fruit industry, specifically peach production, in West Virginia, while root-knot nematodes remain a major pest of agricultural crops worldwide. Nematologists are limited in advice available to growers with serious nematode problems, leaving orchards vulnerable to further nematode damage. Current gaps in research on the use of B. firmus as a bionematicide limit the amount of information available for growers to make informed decisions regarding $B$. firmus applications. The nematicidal potential of $B$. firmus has only been researched and reported for a relatively small number of nematode species. By examining the effects of $B$. firmus on dagger and root-knot nematode species indigenous to West Virginia, this study aims at providing information on the efficacy of B. firmus as a bionematicide for fruit bearing trees, such as peaches and apples, in the Mid-Atlantic region of the United States.

Past studies reporting the ability of $B$. firmus to control root-knot nematode populations have considered the interaction between the bacterium and tropical root-knot nematode species such as Meloidogyne incognita and M. javanica, therefore, little is known about the nematicidal effects of B. firmus on the temperate root-knot nematode species, M. hapla. It is also unclear whether $B$. firmus limits root-knot nematode infection through the production of toxic chemicals that are lethal to the nematodes, or through interactions with host plant roots that alter root-knot nematode parasitic behavior. In this study, various direct toxicity and attraction assays were performed to determine how the presence of $B$. firmus impacts the mortality and behavior of $M$. hapla. Likewise, little is known about the use of $B$. firmus as an effective bionematicide for the control of Xiphinema americanum, or whether the mode of action employed by B. firmus to control X. americanum is similar to that with Meloidogyne.

The project documented in this thesis consisted of two studies, both of which involved determining the effect of $B$. firmus on species of plant-parasitic nematodes indigenous to West 
Virginia orchards. The first study (Chapter 2) had two objectives: 1) to determine if $B$. firmus is an effective bionematicide for the control of Meloidogyne hapla; and 2) to verify the mode of action employed by B. firmus to control M. hapla J2s. The second study (Chapter 3) had similar objectives, but aimed to determine the interaction of B. firmus with Xiphinema americanum. In both studies, direct toxicity and attraction assays were performed to determine how the presence of $B$. firmus affects the mortality and behavior of each nematode species. 


\section{References}

Adamu, F., Nimzing, L., and Yahemba, P. 2009. Screening of Bacillus species with potentials of antibiotic production. Applied Medical Informatics. 24:42-46.

Bajaj, B. K., and Manhas, K. 2012. Production and characterization of xylanase from Bacillus licheniformis P11 (C) with potential for fruit juice and bakery industry. Biocatalysis and Agricultural Biotechnology 4:330-337.

Barbosa, D. H. S. G., Vieira, H. D., Souza, R. M., Viana, A. P., and Silva, C. P. 2004. Field estimates of coffee yield losses and damage threshold by Meloidogyne exigua. Nematologia Brasileira 28:49-54.

Barrat, J., Mircetich, S., and Fogle, H. 1968. Stem pitting of peach. Plant Disease Reporter. 52:91-94.

Bayer CropScience. 2016. Accessed April 25, 2016.

https://www.cropscience.bayer.us/products/seedgrowth/poncho-votivo/the-votivo-solution

Bottone, E. J. 2010. Bacillus cereus, a volatile human pathogen. Clinical Microbiology Reviews 23:382-398.

Bird, A. F. 1962. The inducement of giant cells by Meloidogyne javanica. Nematologica 8:1-10.

Bird, A. F., and Wallace, H. R. 1965. The influence of temperature on Meloidogyne hapla and M. javanica. Nematologica 11:581-589.

Brown, D. J. F. 1986. Reproduction and inter-breeding within and between populations of Xiphinema diversicaudatum (Nematoda: Dorylaimoidea). Nematologia Mediterranea 14:73-82.

Brown, D. J. F., and Coiro, M. I. 1983. The total reproductive capacity and longevity of individual female Xiphinema diversicaudatum (Nematoda: Dorylaimida). Nematologia Mediterranea 11:87-92.

Brown, D. J. F., Halbrendt, J. M., Robbins, R. T., and Vrain, T. C. 1993. Transmission of Nepoviruses by Xiphinema americanum-group nematodes. Journal of Nematology 25:349-354.

Brown, D. J. F., Robertson, W. M., and Trudgill, D. L. 1995. Transmission of viruses by plant nematodes. Annual Review of Phytopathology 33:223-249.

Cano, R. J. and Borucki, M. K. 1995. Revival and identification of bacterial spores in 25-to 40million-year-old Dominican amber. Science 268:1060-1064.

Castillo, J. D., Lawrence, K. S., and Kloepper, J. W. 2013. Biocontrol of the reniform nematode by Bacillus firmus GB-126 and Paecilomyces lilacinus 251 on cotton. Plant Disease 97:967-976. 
Chen, X. H., Koumoutsi, A., Scholz, R., and Borriss, R. 2008. More than anticipated-production of antibiotics and other secondary metabolites by Bacillus amyloliquefaciens FZB42. Journal of Molecular Microbiology and Biotechnology 16:14-24.

Chitwood, D. J., and Perry, R. N. 2009. Reproduction, physiology, and biochemistry. Pp. 182200. In: Perry, R. N., Moens, M., and Starr, J. L. Root-knot nematodes. Wallingford: CAB International.

Cohn, E. 1970. Observations on the feeding and symptomatology of Xiphinema and Longidorus on selected host roots. Journal of Nematology 2:167-173.

Cohn, E., and Mordechai, M. 1969. Investigations on the life cycles and host preference of some species of Xiphinema and Longidorus under controlled conditions. Nematologica 15:295-302.

Crow, W. T. (2014). Effects of a commercial formulation of Bacillus firmus I-1582 on golf course bermudagrass infested with Belonolaimus longicaudatus. Journal of Nematology 46:331335.

Dadwal, V. and Jamaluddin. 2010. Bacillus firmus as bio-controlling agent for seed-borne and nursery pathogens of forest tree species. The Indian Forester 136:158-162.

Diaz, K., Valiente, C., Martinez, M., Castillo, M., and Sanfuentes, E. 2009. Root-promoting rhizobacteria in Eucalyptus globulus cuttings. World Journal of Microbiology and Biotechnology 25:867-873.

Eisenback, J. D., and Hunt, D. J. 2009. General morphology. Pp. 18-54. In: Perry, R. N., Moens, M., and Starr, J. L. Root-knot nematodes. Wallingford: CAB International.

Epstein, I., and Grossowicz, N. 1969. Prototrophic thermophilic bacillus: isolation, properties, and kinetics of growth. Journal of Bacteriology 99:414-417.

Errington, J. 2003. Regulation of endospore formation in Bacillus subtilis. Nature Reviews Microbiology 1:117-126.

Esmenjaud, D., Minot, J. C., Voisin, R., Pinochet, J., and Salesses, G. 1994. Inter-and intraspecific resistance variability in Myrobalan plum, peach, and peach-almond rootstock using 22 root-knot nematode populations. Journal of the American Society for Horticultural Science 119:94-100.

Fernández, C., Pinochet, J., Esmenjaud, D., Salesses, G., and Felipe, A. 1994. Resistance among new Prunus rootstocks and selections to root-knot nematodes in Spain and France. HortScience 29:1064-1067.

Flegg, J. J. M. 1968. Life-cycle studies of some Xiphinema and Longidorus species in southeastern England. Nematologica 14:197-210. 
Georgi, L. L. 1988. Transmission of tomato ringspot virus by Xiphinema americanum and X. rivesi from New York apple orchards. Journal of nematology 20:304-308.

Giannakou, I., Karpouzas, D., and Prophetou-Athanasiadou, D. 2003. A novel non-chemical nematicide for the control of root-knot nematodes. Applied Soil Ecology. 26:69-79.

Gugino, B. K., Abawi, G. S., and Ludwig, J. W. 2006. Damage and management of Meloidogyne hapla using oxamyl on carrot in New York. Journal of Nematology 38:483-490.

Handoo Z.A. 1998. Plant-parasitic nematodes. Accessed March 24, 2016.

http://www.ars.usda.gov/Main/docs.htm?docid=9628\&pf=1\&cg_id=0

Höfte, H., and Whiteley, H. R. (1989). Insecticidal crystal proteins of Bacillus thuringiensis. Microbiological Reviews, 53:242-255.

Hussain, M. A., Mukhtar, T., and Kayani, M. Z. 2011. Assessment of the damage caused by Meloidogyne incognita on okra (Abelmoschus esculentus). Journal of Animal and Plant Science 21:857-861.

Jaffee, B. A., Harrison, M. B., Shaffer, R. L., and Strang, M. B. 1987. Seasonal population fluctuation of Xiphinema americanum and $X$. rivesi in New York and Pennsylvania orchards. Journal of nematology 19:369-378.

Jones, M. G. K. 1981. Host cell responses to endoparasitic nematode attack: structure and function of giant cells and syncytia. Annals of Applied Biology 97:353-372.

Kariuki, G. M., Dickson, D. W., and Brito, J. A. 2006. Effects of Pasteuria penetrans endospore rate of attachment on root penetration and fecundity of Meloidogyne arenaria race 1.

Nematropica 36:261-267

Keren-Zur, M., Antonov, J., Bercovitz, A., Feldman, K., Husid, A., Kenen, G., Marcov, N., and Rebhun, M. 2000. Bacillus firmus formulations for the safe control of root-knot nematodes. The BCPC conference: Pests and diseases. 1:47-52. UK: British Crop Protection Council.

Koenning, S., Overstreet, C., Noling, J., Donald, P., Becker, J., and Fortnum, B. 1999. Survey of crop losses in response to phytoparasitic nematodes in the United States for 1994. Journal of Nematology 31:587-618.

Kotcon, J. 1990. Distribution, frequency, and population density of nematodes in West Virginia peach orchards. Journal of Nematology. 22:712-717.

Lahtinen, A. E., Trudgill, D. L., and Tlikkala, K. 1988. Threshold temperature and minimum thermal time requirements for the complete life cycle of Meloidogyne hapla from Northern Europe. Nematologica 34:443-451. 
Leelasuphakul, W., Hemmanee, P., and Chuenchitt, S. 2008. Growth inhibitory properties of Bacillus subtilis strains and their metabolites against the green mold pathogen (Penicillium digitatum Sacc.) of citrus fruit. Postharvest Biology and Technology 48:113-121.

McKenry, M. V., Kretsch, J. O., and Anwar, S. A. 2001. Interactions of selected rootstocks with ectoparasitic nematodes. American Journal of Enology and Viticulture 52:304-309.

Mendoza, A., Kiewnick, S., and Sikora, R. 2008. In vitro activity of Bacillus firmus against the burrowing nematode Radopholus similis, the root-knot nematode Meloidogyne incognita and the stem nematode Ditylenchus dipsaci. Biocontrol Science and Technology. 18:377-389.

Mendoza, A. and Sikora, R. 2009. Biological control of Radopholus similis in banana by the combined application of the mutualistic endophyte Fusarium oxysporum strain 162, the egg pathogen Paecilomyces lilacinus strain 251 and the antagonistic bacteria Bacillus firmus. BioControl 54:263-272.

Mor (Mordechai), M., and Oka, Y. 2006. Histological study of giant cells formed by the rootknot nematode Meloidogyne artiellia as compared with M. hapla and M. javanica in cabbage, turnip and barley. Phytoparasitica 34:502-509.

Mountain, W., Powell, C., and Forer, L. 1992. A trough system for measuring transmission of tomato ringspot virus by dagger nematodes. HortScience 27:1283-1285.

Nicholson, W. L., Munakata, N., Horneck, G., Melosh, H. J., and Setlow, P. 2000. Resistance of Bacillus endospores to extreme terrestrial and extraterrestrial environments. Microbiology and Molecular Biology Reviews 64:548-572.

Nielsen, P., Fritze, D., and Priest, F. G. 1995. Phenetic diversity of alkaliphilic Bacillus strains: proposal for nine new species. Microbiology 141:1745-1761.

Nyczepir, A. P. 1991. Nematode management strategies in stone fruits in the United States. Journal of Nematology 23:334-341.

Parish, C. L., and Converse, R. H. 1981. Tomato ringspot virus associated with apple union necrosis and decline in western United States. Plant Disease 65:261-263.

Peleg, I. and Feldman, K. 1996. Bacillus firmus CNCM I-1582 or Bacillus cereus CNCM I-1562 for controlling nematodes. U.S. Patent No. 6406690 B1. Washington, DC: U.S. Patent and Trademark Office.

Pezard, C., Berche, P., and Mock, M. 1991. Contribution of individual toxin components to virulence of Bacillus anthracis. Infection and Immunity 59:3472-3477. 
Powell, N. T., Melendez, P. L., and Batten, C. K. 1971. Disease complexes in tobacco involving Meloidogyne incognita and certain soil-borne fungi. Phytopathology 61:1332-1337.

Raski, D. J., Maggenti, A. R., and Jones, N. O. 1973. Location of grapevine fanleaf and yellow mosaic virus particles in Xiphinema index. Journal of Nematology 5:208-2011.

Robinson, A. F. 1995. Optimal release rates for attracting Meloidogyne incognita, Rotylenchulus reniformis, and other nematodes to carbon dioxide in sand. Journal of Nematology 27:42-50.

Sansinenea, E. and Ortiz, A. 2011. Secondary metabolites of soil Bacillus spp. Biotechnology Letters 33:1523-1528.

Schnepf, E., Crickmore, N. V., Van Rie, J., Lereclus, D., Baum, J., Feitelson, J., Zeigler D. R. and Dean, D. H. 1998. Bacillus thuringiensis and its pesticidal crystal proteins. Microbiology and Molecular Biology Reviews 62:775-806.

Sikora, R., Schafer, K., and Dababat, A. 2007. Modes of action associated with microbially induced in planta suppression of plant-parasitic nematodes. Australasian Plant Pathology. 36:124-134.

Singh, S., Pandey, R. K., and Goswami, B. K. 2013. Bio-control activity of Purpureocillium lilacinum strains in managing root-knot disease of tomato caused by Meloidogyne incognita. Biocontrol Science and Technology 23:1469-1489.

Smith, S. H., Stouffer, R. F., and Soulen, D. M. 1973. Induction of stem pitting in peaches by mechanical inoculation with tomato ringspot virus. Phytopathology 63:1404-1406.

Sonenshein, A. L. 2000. Control of sporulation initiation in Bacillus subtilis. Current Opinion in Microbiology 3:561-566.

Starr, J. L., and Mai, W. F. 1976. Predicting on-set of egg production by Meloidogyne hapla on lettuce from field soil temperatures. Journal of Nematology 8:87-88.

Stein, T. 2005. Bacillus subtilis antibiotics: structures, synthesis and specific functions. Molecular Microbiology 56:845-857.

Stouffer, R. F., K. D. Hickey, and M. F. Welsh. 1977. Apple union necrosis and decline. Plant Disease Reporter 61:20-24.

Tang, X. M., Lakay, F. M., Shen, W., Shao, W. L., Fang, H. Y., Prior, B. A., Wang, Z. X., and Zhuge, J. 2004. Purification and characterization of an alkaline protease used in tannery industry from Bacillus licheniformis. Biotechnology Letters 26:1421-1424. 
Taylor, C. and Robertson, W. 1970. Sites of virus retention in the alimentary tract of the nematode vectors, Xiphinema diversicaudatum and X. index. Annals of Applied Biology 66:375380 .

Taylor, C. E. and Raski, D. J. 1964. On the transmission of grape fanleaf by Xiphinema index. Nematologica 10:489-495.

Terefe, M., Teferaera, T., and Sakhuja, P. 2009. Effect of a formulation of Bacillus firmus on root-knot nematode Meloidogyne incognita infestation and the growth of tomato plants in greenhouse and nursery. Journal of Invertebrate Pathology 100:94-99.

Turnbull, P. C. 1996. Bacillus. Chapter 15. In: Medical Microbiology $4^{\text {th }}$ edition. Baron, S., editor. Galveston, Texas.

Ventosa, A., Garcia, M. T., Kamekura, M., Onishi, H., and Ruiz-Berraquero, F. 1989. Bacillus halophilus sp. nov., a moderately halophilic Bacillus species. Systematic and Applied Microbiology 12:162-166.

Vrain, T. C., Barker, K. R., and Holtzman, G. I. 1978. Influence of low temperature on rate of development of Meloidogyne incognita and M. hapla larvae. Journal of Nematology 10:166-171.

Wang, C., Lower, S., and Williamson, V. M. 2009. Application of Pluronic gel to the study of root-knot nematode behaviour. Nematology 11:453-464.

Walters, S. A., and Barker, K. R. 1994. Current distribution of five major Meloidogyne species in the United States. Plant Disease 78:772-774.

Wei, J. Z., Hale, K., Carta, L., Platzer, E., Wong, C., Fang, S. C., and Aroian, R. V. 2003. Bacillus thuringiensis crystal proteins that target nematodes. Proceedings of the National Academy of Sciences 100:2760-2765.

Weischer, B. and Wyss, U. 1976. Feeding behaviour and pathogenicity of Xiphinema index on grapevine roots. Nematologica 22:319-325.

Welkos, S. L., Keener, T. J., and Gibbs, P. H. 1986. Differences in susceptibility of inbred mice to Bacillus anthracis. Infection and Immunity 51:795-800.

Wesemael, W. M., Viaene, N., and Moens, M. 2011. Root-knot nematodes (Meloidogyne spp.) in Europe. Nematology 13:3-16.

Wilson, J. and Jackson, T. 2013. Progress in the commercialization of bionematicides. BioControl 58:715-722.

Wyss, U., Grundler, F. M., and Munch, A. 1992. The parasitic behaviour of second-stage juveniles of Meloidogyne incognita in roots of Arabidopsis thaliana. Nematologica 38:98-111. 
Zuckerman, B. M., and Jansson, H. 1984. Nematode chemotaxis and possible mechanisms of host/prey recognition. Annual Review of Phytopathology 22:95-113. 


\section{CHAPTER 2}

\section{EFFICACY AND MODE OF ACTION OF BACILLUS FIRMUS AS A BIONEMATICIDE FOR THE NORTHERN ROOT-KNOT NEMATODE, MELOIDOGYNE HAPLA}

\section{Introduction}

Root-knot nematodes of the genus Meloidogyne are sedentary endoparasites that infect a variety of host plants, many of which are important agricultural crops. The infective larval stage (J2) of these nematodes is attracted to various volatile and soluble root exudates released into the soil (Linford, 1939; Perry, 2005). The attractiveness of these chemicals prompts migration towards the host plant and penetration of the roots near the zone of elongation. Once inside the roots, female root-knot nematodes remain sedentary, molting into a mature, reproductive adult and feeding on five-seven multinucleated giant cells that develop in response to nematode salivary secretions (Favery et al., 2016). Each mature female may produce more than 1000 eggs within their lifetime.

Root-knot nematode infection induces gall formation in host tissues and disrupts the flow of nutrients, causing mild to severe damage and potentially death to host plants. It is estimated that plant-parasitic nematodes are responsible for billions of dollars in crop damage annually (Handoo, 1998). Management of root-knot nematode populations often involves the combination of several pest management practices, though some options can be inappropriate and ineffective for situations such as fruit tree production. In these cases, chemical nematicides remain the best defense. In recent years, however, many chemical nematicides have been banned or are actively being phased out due to harmful environmental effects and human and animal toxicity. With the exception of the insecticide spirotetramat (Movento), there are presently no chemical nematicides registered for use on bearing fruit trees in the United States. Thus, environmentally benign options such as biological controls are needed.

Various soil dwelling bacteria have demonstrated success in controlling root-knot nematode populations. These antagonistic organisms employ different methods, such as direct toxicity and disrupting host finding ability, to limit the severity of nematode infection within plants. Bacillus firmus, a gram-positive endospore-forming bacterium is the active ingredient in a nematicide currently marketed by Bayer CropScience. This organism has been shown to be effective at reducing gall formation and egg hatch, and increasing mortality of root-knot nematodes. Current 
literature available on the efficacy of $B$. firmus is limited to the effects seen on tropical root-knot nematode species, such as $M$. javanica and $M$. incognita, therefore, little is known about the bionematicidal effects of B. firmus on temperate Meloidogyne species such as M. hapla. In addition, the bacterium's nematicidal mode of action remains uncertain. Understanding $B$. firmus's antagonistic relationship towards M. hapla can help establish more effective treatment plans for growers facing root-knot nematode infestations in temperate climates, such as those located in the state of West Virginia.

Peach and apple production is a multi-million dollar business in West Virginia and other mid-Atlantic states (USDA, 2015), though growers facing M. hapla infestations have few options short of chemical intervention. The goal of this study was to determine if $B$. firmus has

potential for controlling infection by the northern root-knot nematode $M$. hapla, and to elucidate a nematicidal mode of action for the bacterium.

\section{Materials and methods}

\section{Bacillus firmus}

A research grade formulation containing a minimum of $1.0 \times 10^{11} \mathrm{CFU} / \mathrm{gram}$ of Bacillus firmus (I-1582) provided by Bayer CropScience was used in this study. A Bacillus isolate from this formulation (named BF1) was selected and the identity was confirmed using a range of morphological and biochemical characteristics analogous to B. firmus (Appendix 1). Later, rRNA gene analysis of the BF1 isolate resulted in 100\% identity with Bacillus cereus, Bacillus thuringiensis, and Bacillus anthracis and 93\% identity with Bacillus firmus (Appendix 1). For the following experiments, the isolated BF1 culture is referred to as B. firmus. It was grown in $100 \mathrm{~mL}$ of TSB at $28^{\circ} \mathrm{C}$ for 24 hours to produce a concentration of approximately $10^{7} \mathrm{CFU} / \mathrm{mL}$. The day-old culture was centrifuged at $5000 \mathrm{rpm}$ for 20 minutes to separate bacterial cells and TSB. The supernatant was removed and the B. firmus cells were re-suspended in $100 \mathrm{~mL}$ of sterile soil extract (SSE).

\section{Sterile soil extract (SSE)}

Sterile soil extract (SSE) was used as the control for all experiments in this study. SSE was used in lieu of sterile distilled water and TSB based on preliminary results that exhibited a larger nematode mortality rate for both cell-free sterile distilled water and cell-free TSB when 
compared to cell-free SSE. SSE was prepared by combining $1000 \mathrm{~g}$ of a Tilsit silt loam soil obtained from the West Virginia University Organic Farm in $1 \mathrm{~L}$ of tap water. The soil and water were mixed thoroughly then allowed to settle for 24 hours. The water was decanted and autoclaved twice for 90 minutes each time.

\section{Meloidogyne hapla}

Root-knot nematodes used for this experiment were extracted from a pure culture (\#16) of M. hapla isolated from strawberry from Monongalia County, WV. M. hapla was maintained on tomato roots as part of the nematode culture collection at West Virginia University. Perineal patterns were used to verify the M. hapla culture. Tomato roots were washed free of debris and eggs were extracted by submerging roots in $1 \% \mathrm{NaClO}$ and shaking vigorously for 4 minutes. The resulting suspension was washed through stacked sieves with 250 and $25 \mu \mathrm{m}$ pore mesh (Hussey and Barker, 1973). Nematode eggs were placed in Baermann funnels and 1-5 day old $\mathrm{J} 2 \mathrm{~s}$ were used for the following experiments.

\section{Tomato seedlings}

Rutgers tomato seeds were surface disinfested by washing in a $70 \%$ ethanol solution for 2 minutes, then a $3 \% \mathrm{NaOCl}$ solution for 10 minutes and immediately rinsing with sterile distilled water three times. Seeds were transferred to $0.75 \%$ trypticase soy agar (TSA) plates and incubated at $28^{\circ} \mathrm{C}$ for 5 days or until roots were approximately $2-4 \mathrm{~cm}$. Seedlings that showed signs of microbial contamination were discarded.

\section{Experiment 1. Bacillus firmus direct toxicity assay}

To assess whether B. firmus was directly toxic to nematodes, we tested the hypothesis that $M$. hapla survival differed among various concentrations of $B$. firmus in solution. A $10^{7}$ $\mathrm{CFU} / \mathrm{mL}$ concentration of $B$. firmus in SSE was serially diluted to produce seven B. firmus concentrations from approximately $10^{1}$ to $10^{7} \mathrm{CFU} / \mathrm{mL}$. Bacterial concentrations were enumerated using serial dilution and spread plating. Two $\mathrm{mL}$ of each bacterial concentration were added to 35-mm plastic dishes and uniformly spread throughout the plates. Plates with cellfree SSE were used as a control. Approximately $10 \mathrm{M}$. hapla J2s were added to each dish and the plates were incubated in darkness at room temperature $\left(23 \pm 2^{\circ} \mathrm{C}\right)$. Nematode mortality was 
determined at 24, 48, and 72 hours. Nonmotile nematodes were probed with a fine needle and those that did not respond were considered dead. Four replications were used for each B. firmus concentration and the entire experiment was conducted three times.

\section{Experiment 2. Filter paper attraction assay}

To determine if the movement of root-knot nematodes is affected by the presence of $B$. firmus, we tested the hypothesis that the number of $M$. hapla J2s that accumulate near B. firmus will differ from that accumulating near the SSE control. Sterile filter paper disks (12.7 $\mathrm{mm}$ dia) were soaked in either a $10^{7} \mathrm{CFU} / \mathrm{mL}$ concentration of B. firmus in SSE or cell-free SSE. Approximately $2 \mathrm{~mL}$ of a $23 \%$ Pluronic gel medium was pipetted onto 75 X 25-mm glass microscope slides, covering the entire surface. The slides were partitioned into three labeled sections: B. firmus (32.5 X $25 \mathrm{~mm})$, center (10 X $25 \mathrm{~mm})$, and SSE (32.5 X $25 \mathrm{~mm})$. Treated filter paper disks were immediately placed towards the edges of either the B. firmus or SSE sections of the slides, approximately $40 \mathrm{~mm}$ apart. No filter paper disks were placed in the centers. The slides were placed in petri dishes with a dampened paper towel and incubated at $28^{\circ} \mathrm{C}$ for 1 hour. After incubation, approximately 150 M. hapla J2s were added to the center of each slide (Figure 1). The slides with nematodes were again incubated in darkness at room temperature $\left(23 \pm 2^{\circ} \mathrm{C}\right)$. The number of nematodes in each section of the slide was counted at 1,2 , 4 and 24 hours post inoculation. The experiment had eight replicates.

\section{Experiment 3. Tomato seedling attraction assay}

To determine if the migration of $M$. hapla towards host plant roots is altered by the presence of B. firmus, we tested the hypothesis that a smaller number of $M$. hapla J2s will accumulate near B. firmus-treated roots compared with SSE-treated roots. The roots of surface disinfested tomato seedlings were submerged in either a $10^{7} \mathrm{CFU} / \mathrm{mL}$ concentration of $B$. firmus in SSE or cell-free SSE. Approximately $2 \mathrm{~mL}$ of a $23 \%$ Pluronic gel medium was pipetted onto 75 X 25-mm glass microscope slides, covering the entire surface. The slides were partitioned into three labeled sections: B. firmus ( $32.5 \times 25 \mathrm{~mm})$, center (10 X $25 \mathrm{~mm})$, and SSE ( 32.5 X 25 $\mathrm{mm}$ ). One tomato seedling from each treatment was immediately placed towards the edge of the appropriate section on the slides approximately $50 \mathrm{~mm}$ apart. No tomato seedlings were placed in the centers. The slides were placed in petri dishes with a dampened paper towel and incubated 
at $28^{\circ} \mathrm{C}$ for 1 hour. After incubation, approximately $150 \mathrm{M}$. hapla J2s were added to the center of each slide and the slides were stored in darkness at room temperature $\left(23 \pm 2^{\circ} \mathrm{C}\right)$. The nematodes in each section of the slide were counted at 1,2, 4 and 24 hours. The experiment had five replicates.

\section{Experiment 4. In-vitro infection assay}

To determine if root penetration by M. hapla was influenced by the presence of B. firmus, we tested the hypothesis that fewer M. hapla J2s will successfully penetrate B. firmus-treated roots compared with SSE-treated roots. Tomato seedling roots were submerged in either a $10^{7}$ $\mathrm{CFU} / \mathrm{mL}$ concentration of B. firmus in SSE or cell-free SSE. Approximately $2 \mathrm{~mL}$ of a $23 \%$ Pluronic gel medium was pipetted onto 75 X 25 -mm glass microscope slides, covering the entire surface. One seedling of either the B. firmus treatment or the SSE treatment was added to each slide. Slides were placed in petri dishes with a dampened paper towel and incubated at $28^{\circ} \mathrm{C}$ for 1 hour. After incubation, approximately $150 \mathrm{M}$. hapla J2s were added to each slide close to the root tips. The slides were incubated in darkness at room temperature $\left(23 \pm 2^{\circ} \mathrm{C}\right)$. At 48 hours post inoculation, each tomato seedling was removed from the gel medium and the roots were stained by bleaching in a $1.5 \% \mathrm{NaOCl}$ solution for 4 minutes, rinsing with distilled water, and boiling with acid fuchsin stain for 30 seconds (Byrd et al., 1983). J2s that had successfully penetrated the roots were counted. Ten replications were used for each treatment.

\section{Experiment 5. In-sand attraction assay (5-day)}

To determine if root-knot infection in tomato roots in sand is disrupted by the presence of $B$. firmus, we tested the hypothesis that fewer $M$. hapla $\mathrm{J} 2 \mathrm{~s}$ will successfully penetrate the roots of B. firmus-treated roots compared with SSE-treated roots. Tomato seedling roots were submerged in either a $10^{7} \mathrm{CFU} / \mathrm{mL}$ concentration of B. firmus in SSE or cell-free SSE. Two tomato seedlings, one of each treatment, were planted on either side of a beaker (approximately $35 \mathrm{~mm}$ apart) containing $50 \mathrm{~g}$ of sterile sand with a $10 \%$ moisture content (approximately field capacity) (Figure 2). The tomato seedlings were left on a laboratory bench top under lights for 1 day before being inoculated with approximately $500 \mathrm{M}$. hapla J2s in the center of each beaker. The plants were left on the bench for an additional 5 days receiving 16 hours of light over a 24hour period. The seedlings were then removed from the sand, gently washed free of debris and 
the roots were stained. The number of nematodes that successfully penetrated the roots was determined. Ten replicates were used for each treatment.

\section{Experiment 6. In-sand reproduction assay (40-day)}

To determine if $B$. firmus can decrease the severity of $M$. hapla infection in tomato roots, we tested the hypothesis that B. firmus-treated roots will contain fewer M. hapla females and eggs per gram of root compared with SSE-treated root. Tomato seedling roots were submerged in either a $10^{7} \mathrm{CFU} / \mathrm{mL}$ concentration of B. firmus in SSE or cell-free SSE. Two seedlings, one from each treatment, were planted on either side of a beaker (approximately $35 \mathrm{~mm}$ apart) containing $50 \mathrm{~g}$ of sterile sand with a 10\% moisture content (approximately field capacity). The seedlings were left on a laboratory bench top under lights for 1 day before being inoculated with approximately $500 \mathrm{M}$. hapla J2s in the center of each beaker. After 5 days, the seedlings were separated and transplanted into individual beakers containing $500 \mathrm{~g}$ of sterile sand. The plants were left on the bench top at room temperature $\left(23 \pm 2^{\circ} \mathrm{C}\right)$ receiving 16 hours of light over a 24hour period and fertilizer every 3 days. After 40 days the plants were removed from their beakers, the roots were washed free of debris, and M. hapla eggs were extracted and counted. Roots were stained with acid fuchsin as described in the infection assay above and the number of visible females was determined. Shoot weight, dry shoot weight, and root weight were also recorded. The experiment was conducted once with 20 replicates per treatment.

\section{Data Analysis}

All data were analyzed using JMP and SAS software (JMP®, Version Pro 11, SAS Institute Inc., Cary, NC, Copyright (C2013; SAS®, Version 9.3, SAS Institute Inc., Cary, NC, Copyright (C2002-2010). The significance criterion (alpha) for all tests was 0.05 unless otherwise indicated.

\section{Results}

Experiment 1. B. firmus direct toxicity assay

As the concentration of $B$. firmus increased from cell-free to approximately $10^{7} \mathrm{CFU} /$ $\mathrm{mL}$, plates became increasingly cloudy and visibility was impacted by the bacterial composition. Nematodes exposed to higher concentrations of B. firmus, specifically the two highest 
concentrations of approximately $10^{7}$ and $10^{6} \mathrm{CFU} / \mathrm{mL}$ were typically less active and required probing to verify living status more often than J2s in cell-free SSE. Due to the significant negatively skewed distribution, data were analyzed using a Kruskal-Wallis test by ranks and treatment means were compared with the control using the Steel ranks test. Differences among treatments were not statistically significant at 24 hours $(P=0.29)$ but by 48 hours there was a significant difference in M. hapla survival in dishes with $10^{7} \mathrm{CFU} / \mathrm{mL}$ compared to the control $(P=0.02)$. Exposure to $10^{7} \mathrm{CFU} / \mathrm{mL}$ of $B$. firmus yielded a $15 \%$ decrease in the proportion of living nematodes by 72 hours (Figure 2.3$)$ compared to the control $(P<0.01)$.

\section{Experiments 2 and 3 . Attraction assays}

Nematode movement from the center of each slide was observed within the first hour, though $50 \%$ or more of the nematodes remained in the center throughout the length of the experiment. Most nematode movement occurred in the direction of the SSE control for both filter paper and tomato seedling attraction assays. Tracks made by nematodes moving along the surface of the Pluronic gel medium were visible but were rarely seen in the B. firmus section of slides. Data were analyzed using a repeated measures ANOVA with irregular spacing (due to unequally spaced time points), using spatial Gaussian covariance structure. Time was considered the covariate. The attraction assays using filter paper showed a significant treatment effect over time ( $\mathrm{P}<0.01$, Figure 2.4). After 24 hours, $16 \%$ of motile J2s were on the B. firmus portion of the slides compared to $93 \%$ of motile J2s at the SSE control. Attraction assays using tomato seedlings were similar with $29 \%$ of motile J2s on the B. firmus portion of the slides compared to $71 \%$ at the SSE control $(\mathrm{P}=0.01$, Figure 2.5$)$.

\section{Experiment 4. In-vitro infection assay}

By 48 hours after nematodes were introduced to tomato roots on Pluronic gel, stained J2s within roots were clearly visible using a stereoscopic microscope. Data were analyzed using the nonparametric Kruskal-Wallis test by ranks because the distribution was not normal. Root infection by $\mathrm{J} 2 \mathrm{~s}$ was significantly greater in the control treatment group $(P=0.01)$ than roots treated with a $B$. firmus concentration of $10^{7} \mathrm{CFU} / \mathrm{mL}$ (Figure 2.6). On average, $20 \mathrm{~J} 2 \mathrm{~s}$ successfully penetrated SSE-treated roots compared with three J2s in B. firmus-treated roots. 


\section{Experiment 5. In-sand attraction assay 5-day}

Root-knot nematode infection was apparent in tomato roots of both treatment groups at 5 days post inoculation. Data were analyzed using a matched pairs t-test analysis. Roots treated with a $10^{7} \mathrm{CFU} / \mathrm{mL}$ concentration of $B$. firmus had fewer $\mathrm{J} 2 \mathrm{~s}$ than the control $(P=0.09$, Figure 2.7). On average, $79 \mathrm{~J} 2 \mathrm{~s}$ successfully penetrated SSE-treated roots compared with $58 \mathrm{~J} 2 \mathrm{~s}$ in $B$. firmus-treated roots.

Experiment 6. In-pot reproduction assay 40-day

At the end of the 40-day trial, tomato plants in both treatment groups showed typical root galling. Data (females per plant and eggs per female) were analyzed using a matched pairs t-test analysis. A slightly larger number of female root-knot nematodes were associated with plants from the SSE control group ( $P=0.05$, figure 2.8). An average of 54 females were found within SSE roots versus an average of 43 females found within $B$. firmus roots. The number of eggs produced per $M$. hapla female did not differ significantly between the $B$. firmus treatment and the control ( $P=0.22$, Figures 2.9). Each $M$. hapla female produced an average of 880 eggs within $B$. firmus-treated roots and 704 eggs within SSE-treated roots.

\section{Discussion}

These results indicate that $B$. firmus has the potential to affect infective $M$. hapla nematodes in a biological control context. Exposing M. hapla J2s to a B. firmus concentration of $10^{7} \mathrm{CFU} / \mathrm{mL}$ resulted in a $15 \%$ decrease in living nematodes after 72 hours. Observed nematode mortality may be explained by the production of lethal secondary metabolites by B. firmus. Species within the genus Bacillus are known to produce secondary metabolites that have an array of functions, including those with antimicrobial properties (Niu et al., 2006; Zhang et al., 2012). Yilmaz et al. (2006) showed that 29 tested Bacillus spp. strains were inhibitory to the growth of both gram-negative and gram-positive bacteria. $B$. thuringiensis has been a successful bioinsecticide for over half a century, and produces toxic crystal proteins that form pores within the digestive tract of insects. Wei et al. (2003) revealed that the toxicity of these proteins extends to the phylum Nematoda. The patent submitted for the use of B. firmus as a bionematicide asserted that "....proteolytic and collagenolytic activities play an important role in control of 
nematodes..." (Patent US6406690, Peleg and Feldman, 1996). Terefe et al. (2009) reported that M. incognita exposed to 2.5 and $3 \%$ concentrations of the $B$. firmus product, BioNem WP, resulted in 100\% nematode paralysis after 24 hours, and Mendoza et al. (2008) showed that $100 \%$ cultural filtrates of B. firmus caused 33\% mortality of M. incognita after 24 hours of exposure. Both studies reported higher nematode mortality after exposure to B. firmus culture filtrates than the $15 \%$ nematode mortality observed in the present study. Furthermore, the lethal properties of $B$. firmus were seen only when the bacterial concentration reached $10^{7} \mathrm{CFU} / \mathrm{mL}$, an indication that the potency of any secondary metabolites produced is not very high. These compound would likely be diluted within the rhizosphere and have little effect on nematodes populations in an orchard environment.

Though the statistically significant nematode mortality produced by $10^{7} \mathrm{~B}$. firmus $\mathrm{CFU} / \mathrm{ml}$ may be due to the production of toxic secondary metabolites, another explanation is that high bacterial densities lead to a decrease in oxygen over time. As the $B$. firmus concentrations were increased from $0-10^{7} \mathrm{CFU} / \mathrm{ml}$, the turbidity of SSE increased, leaving plates with the highest B. firmus concentration lined in a thick, cloudy film of bacteria. Such high bacterial concentrations likely results in high oxygen consumption which can cause hypoxic or anoxic conditions. Nematodes are obligate aerobes that rely solely on diffusion of oxygen from the ambient environment, therefore, this lowered oxygen availability can be detrimental. Föll et al. (1999) showed that more than $80 \%$ of Caenorhabditis elegans, a free-living nematode, will die after 72 hours in anoxic conditions and Qiu and Bedding (2000) demonstrated that the ability of infective Steinernema carpocapsae juveniles to survive in decreased oxygen conditions is low when their available energy supply is limited. In the present study, utilizing an additional treatment of cell-free culture filtrates may have confirmed the presence of toxic secondary metabolites. Also, whether nematode mortality in the present study was caused by the production of toxic chemicals or the limited oxygen availability may have been more conclusive if a steady flow of oxygen was provided to plates through the duration of the experiment.

In-vitro attraction assays comparing M. hapla movement on Pluronic gel in the presence of $10^{7}$ B. firmus $\mathrm{CFU} / \mathrm{ml}$ and cell-free SSE on filter paper showed a significant difference between treatments over time. M. hapla $\mathrm{J} 2 \mathrm{~s}$ were consistently more inclined to migrate away from B. firmus towards cell-free SSE. By 24 hours, a large proportion of nematodes could be seen accumulating on the SSE portion of slides. Similar results were seen when B. firmus and 
cell-free SSE were applied to roots of tomato seedlings, though the observed avoidance of $B$. firmus was not as strong. A suggested nematicidal mode of action for rhizobacteria such as $B$. firmus states that bacterial colonization of roots induces systemic resistance and interferes with a plant-parasitic nematode's ability to find a suitable host (Kloepper et al., 2004). In the present study, the presence of $B$. firmus affected the movement of $M$. hapla not only when applied to tomato roots, but when applied to a non-food source (paper discs) as well. While an influence of B. firmus on root exudates cannot be discounted, this observation suggests the production of a chemorepellent by B. firmus.

Chemotaxis is a central feature of nematode food-finding behavior (Linford, 1939; Wieser, 1955; Bird, 1959; Troemel et al., 1997; Wang et al., 2009; Reynolds et al., 2011). Linford (1939) demonstrated that the ability of Meloidogyne spp. J2s to locate suitable hosts is not a random event, but is influenced by the presence of various plant roots, which results in the accumulation of nematodes near the zone of elongation. Zhao et al. (2000) further demonstrated that exudates from different regions of plant roots can have a positive or negative influence on nematodes. While root border cell exudates from various host plants were attractive to $M$. incognita, root tip exudates were repellent. Despite numerous studies on the subject of nematode reactions to various chemotactic factors, the specific plant-based chemical signals involved in nematode chemotaxis remain largely unexplained. It is likely that the phenomenon is governed by complex biochemical mixtures produced by plants and their associated microbiota. Thus, overwhelming the system with large quantities of an introduced organism, such as B. firmus, could affect these biochemical signals and disrupt nematode host finding. Vos et al. (2011) demonstrated this potential with the introduction of mycorrhizal fungi to banana plants. The fungi successfully induced nematode resistance in the host when compared to control plants. In the present study, the avoidance of $M$. hapla J2s towards B. firmus regardless of the absence of an available food source is an interaction occurring in other bacteria/nematode relationships. Höckelmann et al. (2004) demonstrated that cyanobacteria produce various volatile organic compounds that function to drive nematodes to and away from their associated biofilms and Neidig et al. (2011), showed that Pseudomonas fluorescens produces secondary metabolites that act to repel C. elegans.

To further support the evidence that $B$. firmus repels root-knot nematodes and interferes with nematode host-finding, the present study showed that the presence of B. firmus significantly 
decreased M. hapla infection of tomato roots on Pluronic gel compared to roots treated with cellfree SSE. However, when B. firmus and cell-free SSE treatments were applied to tomato seedlings for the 5-day and 40-day in-pot attraction assays in sand, no significant treatment effect was observed, and tomato roots of both treatments showed varying levels of root-knot nematode infection. The inconsistencies between in-vitro and in-pot assays may be a reflection of the efficiency at which chemicals diffuse through media of various textures. Though Pluronic gel is a useful medium in the study of nematodes, as it mimics the three-dimensional structure of soil, the gel texture may alter the diffusion of volatile organic compounds produced by $B$. firmus compared with sand. Volatile organic compounds diffuse through the porous channels within the soil matrix (Reynolds et al., 2011) and diffusion gradients of the chemorepellent may be more complex in three-dimensional films of moisture around sand grains than in the uniform twodimensional gel medium. The coarse texture of sandy soils allows for fast diffusion rates of organic compounds, while the same chemicals may persist on Pluronic gel longer, offering an extended period of nematode repulsion.

Bayer CropScience states that their B. firmus product, VOTiVO, "creates a living barrier that grows with the roots to extend protection through multiple generations of nematodes." Durham (2013) used a rifampicin-resistant B. firmus mutant strain and demonstrated the organism's ability to colonize the rhizosphere, rhizoplane, and endorhiza of corn, soybean, and cotton. Those data, along with the negative association between B. firmus and M. hapla observed in-vitro in the present study, indicate the plausibility of the "living barrier" hypothesis, though additional in-vitro experiments are needed to determine the specific interactions.

The present study presents evidence of the biocontrol potential of B. firmus, however, the results of these in-vitro and in-pot experiments give little insight into the interactions between $B$. firmus and root-knot nematodes within an orchard setting. Future studies utilizing non-sterilized soil collected from peach orchards would help determine if the presence of native microorganisms has an effect on the ability of $B$. firmus to repel nematodes and suppress infection as seen in the present study. Attraction assays on peach seedlings as well as orchard studies spanning several growing seasons would give a more meaningful assessment on the efficacy of utilizing B. firmus as a bionematicide in West Virginia peach orchards. Having a better understanding of the complex relationships between nematodes and antagonistic organisms, such as the interactions between $M$. hapla and B. firmus, will ultimately support the 
development of more effective biological control options and more efficient pest management plans for growers. 


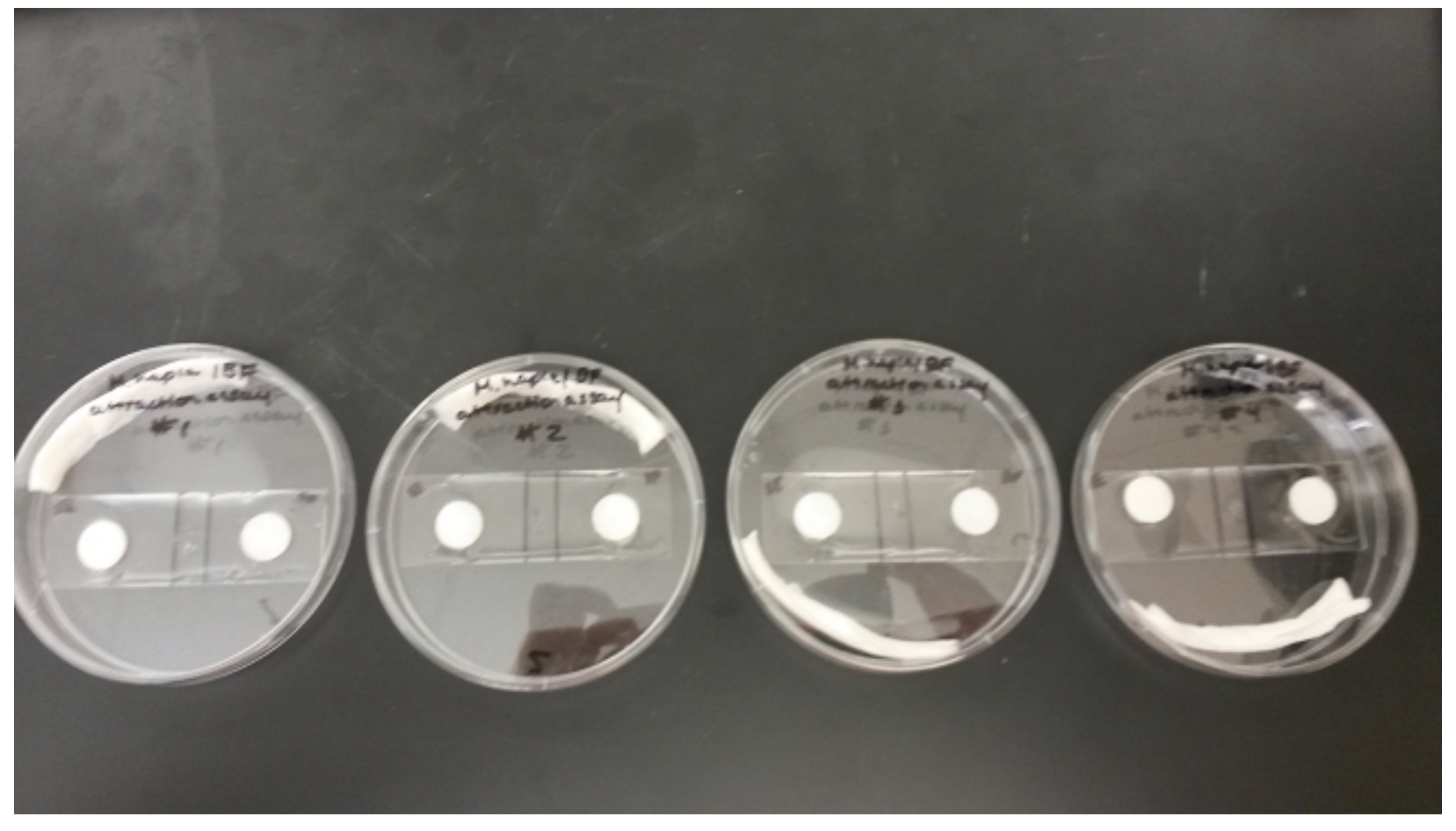

Fig. 2.1. In-vitro attraction assay set-up: B. firmus- and SSE-treated filter paper on opposite ends of slides covered in Pluronic gel. 


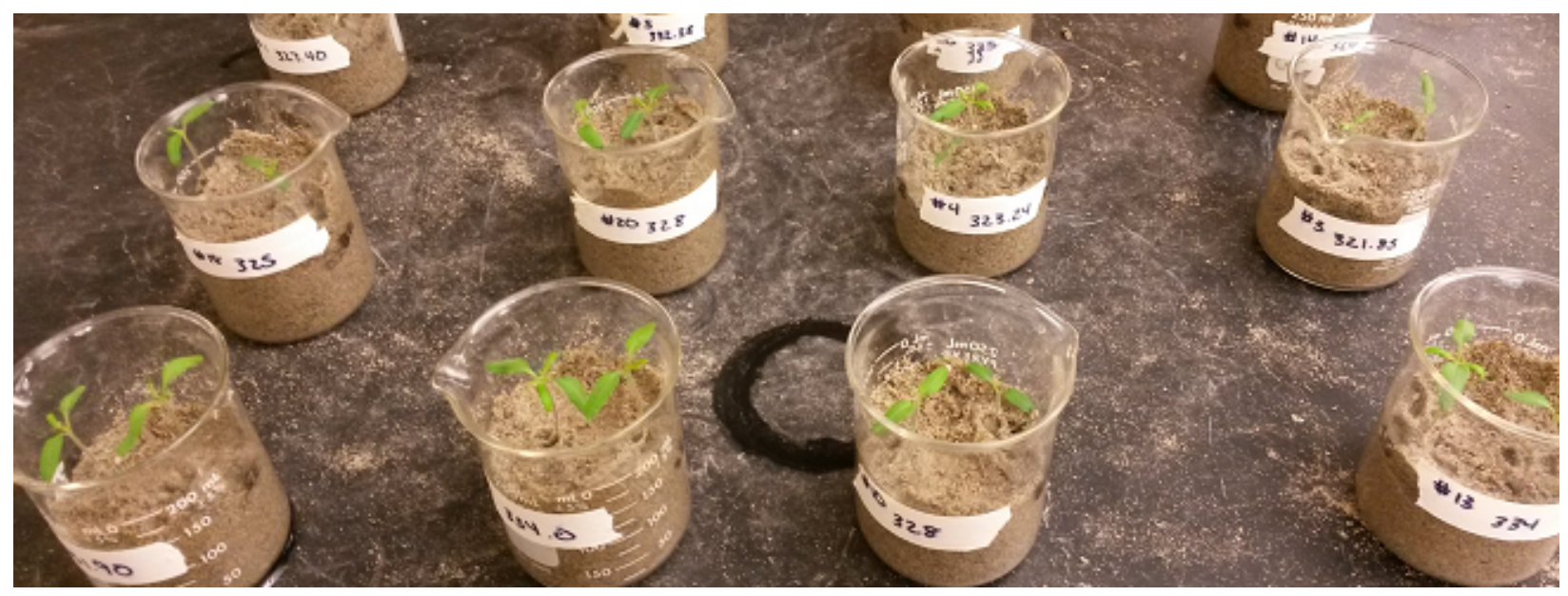

Fig. 2.2. In-pot attraction assay set-up: Beakers containing both $B$. firmus- and SSE-treated tomato seedlings on opposite sides. 


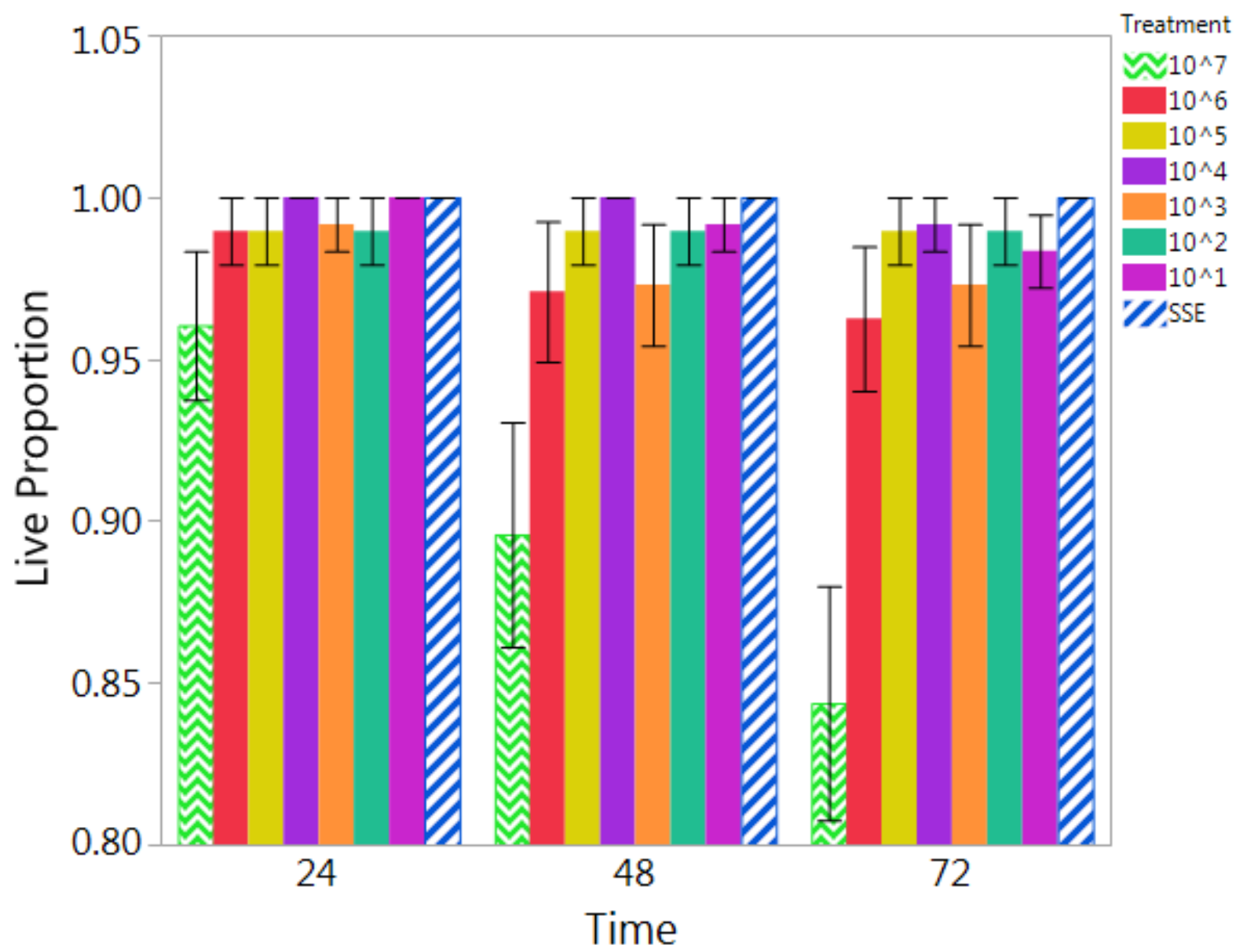

Fig. 2.3. Direct toxicity assay: Proportion of living M. hapla nematodes after 24,48 , and 72 hours of exposure to different concentrations of B. firmus. Error bars represent standard error of the mean. 


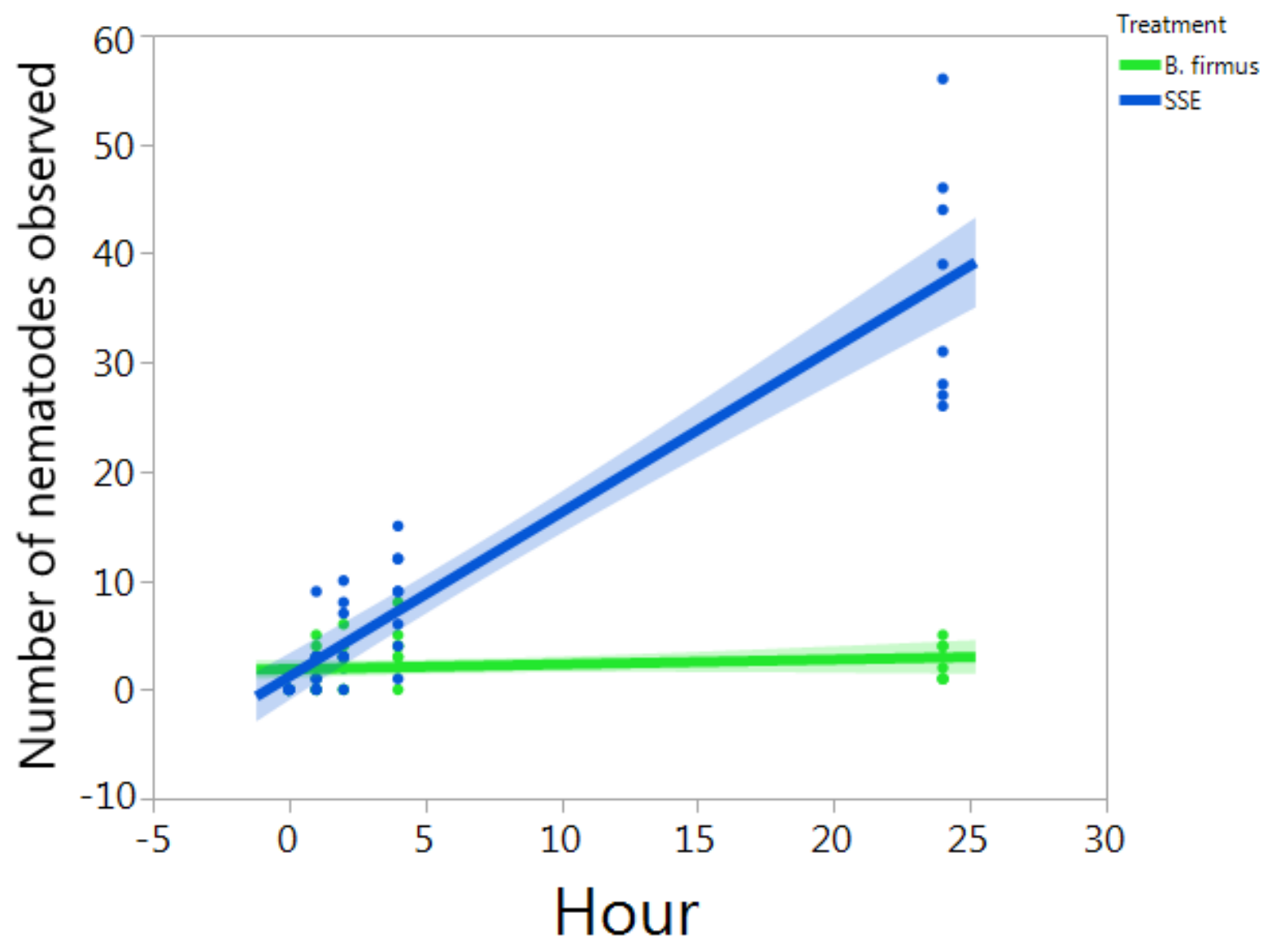

Fig. 2.4. Filter paper attraction assay: Number of $M$. hapla nematodes observed on the $B$. firmus portion of the slide vs. the SSE portion of the slide over time. The shaded regions represent confidence intervals of the slope. 


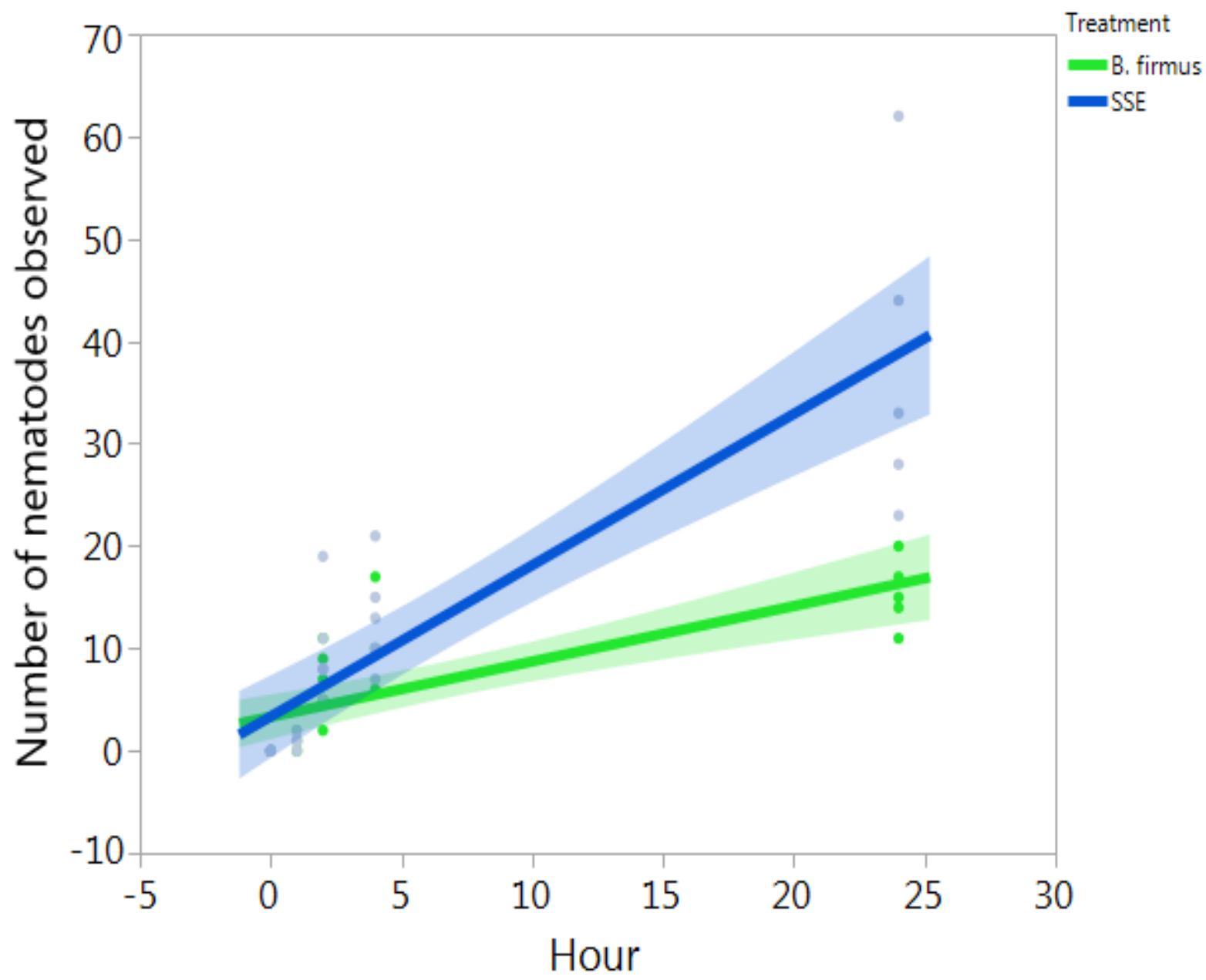

Fig. 2.5. Tomato seedling attraction assay: Number of $M$. hapla nematodes observed on the $B$. firmus portion of the slide vs. the SSE portion of the slide over time. The shaded regions represent confidence intervals of the slope. 


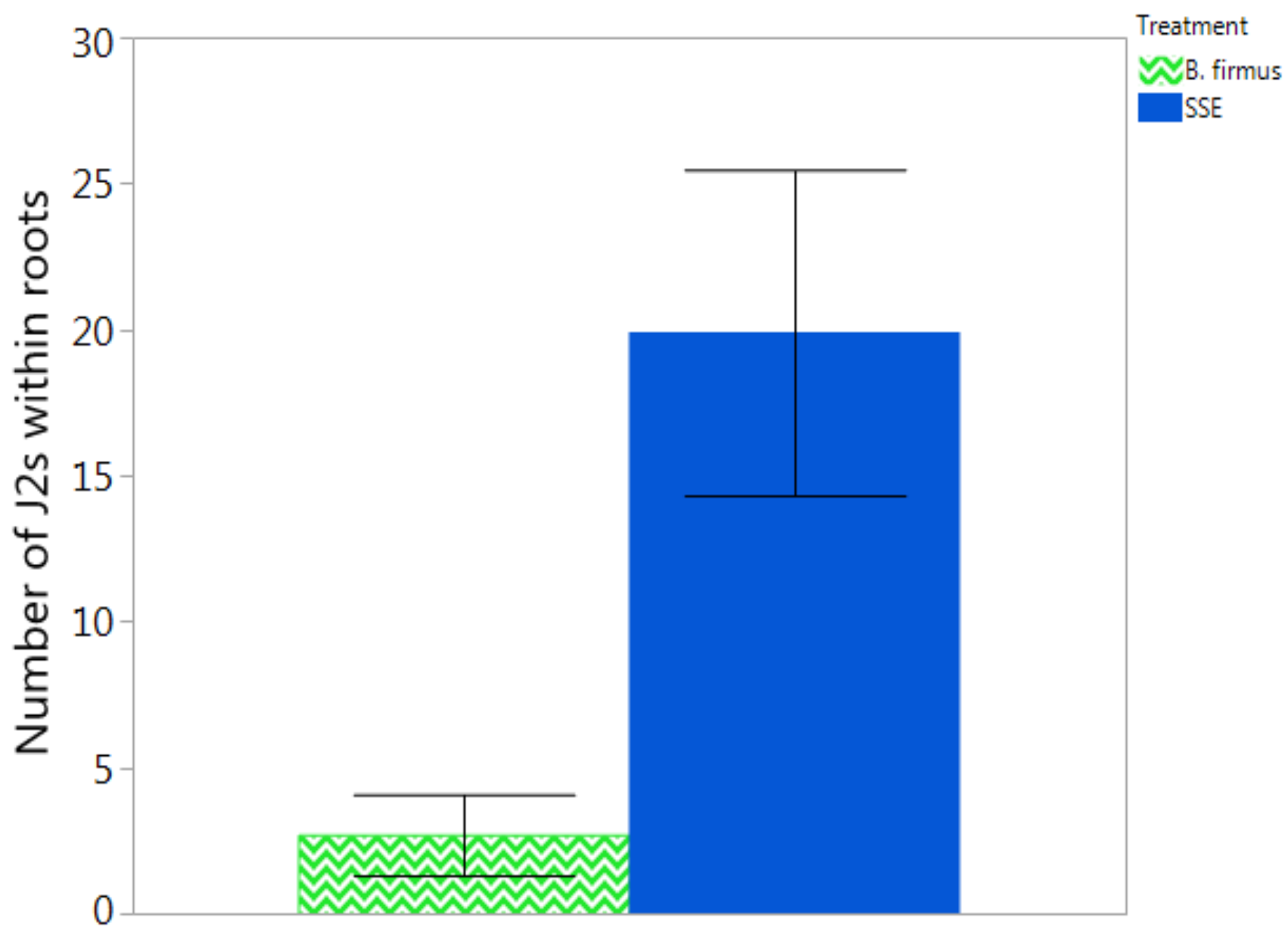

Fig. 2.6. In-vitro infection assay: The average number of $M$. hapla nematodes that successfully penetrated roots of $B$. firmus-treated tomato seedlings vs. SSE-treated tomato seedlings. Error bars represent standard error of the means. 


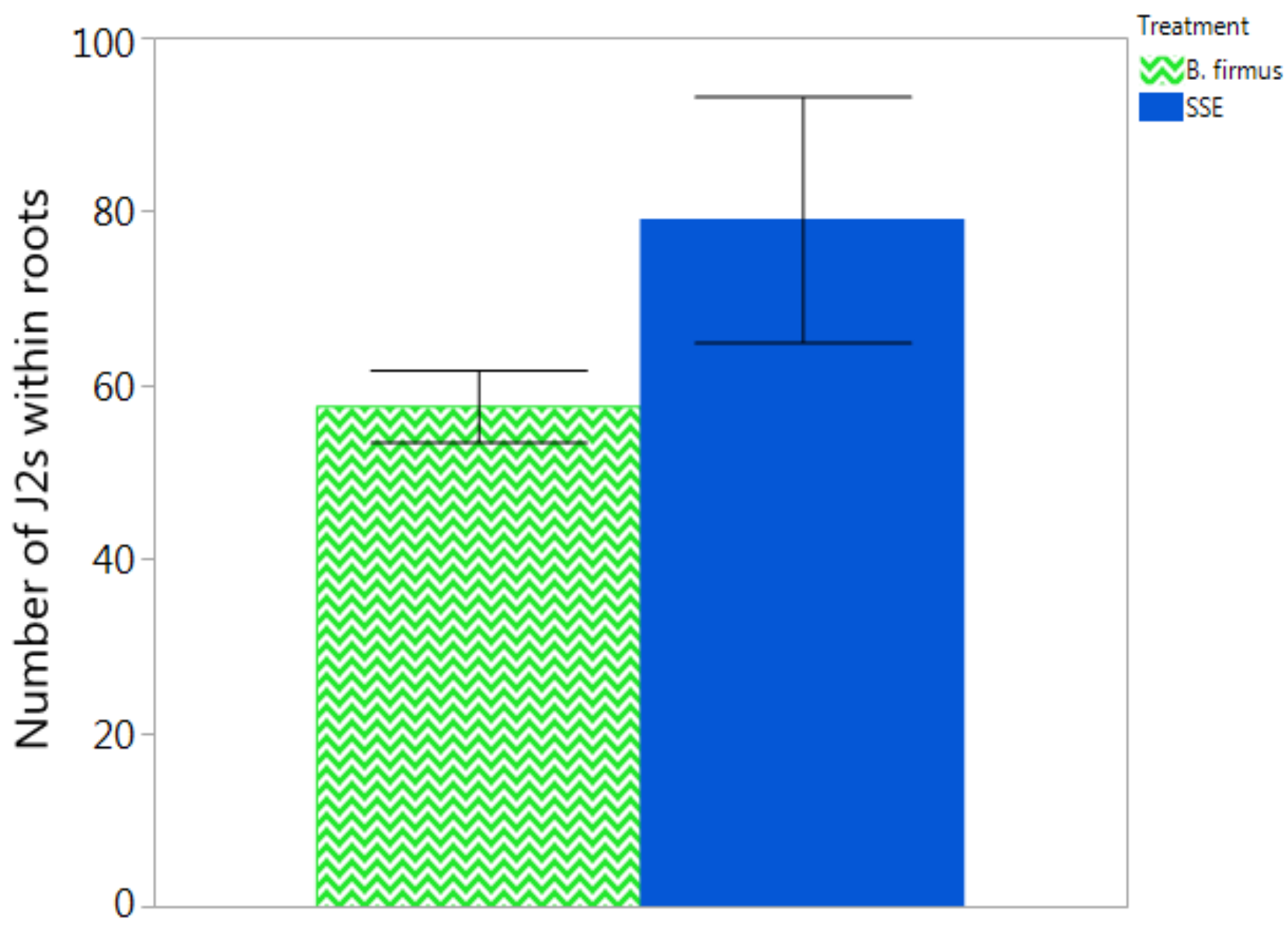

Fig. 2.7. In-sand attraction assay (5-day): The average number of $M$. hapla nematodes that successfully penetrated roots of $B$. firmus-treated tomato seedlings vs. SSE-treated tomato seedlings. Error bars represent standard error of the means. 


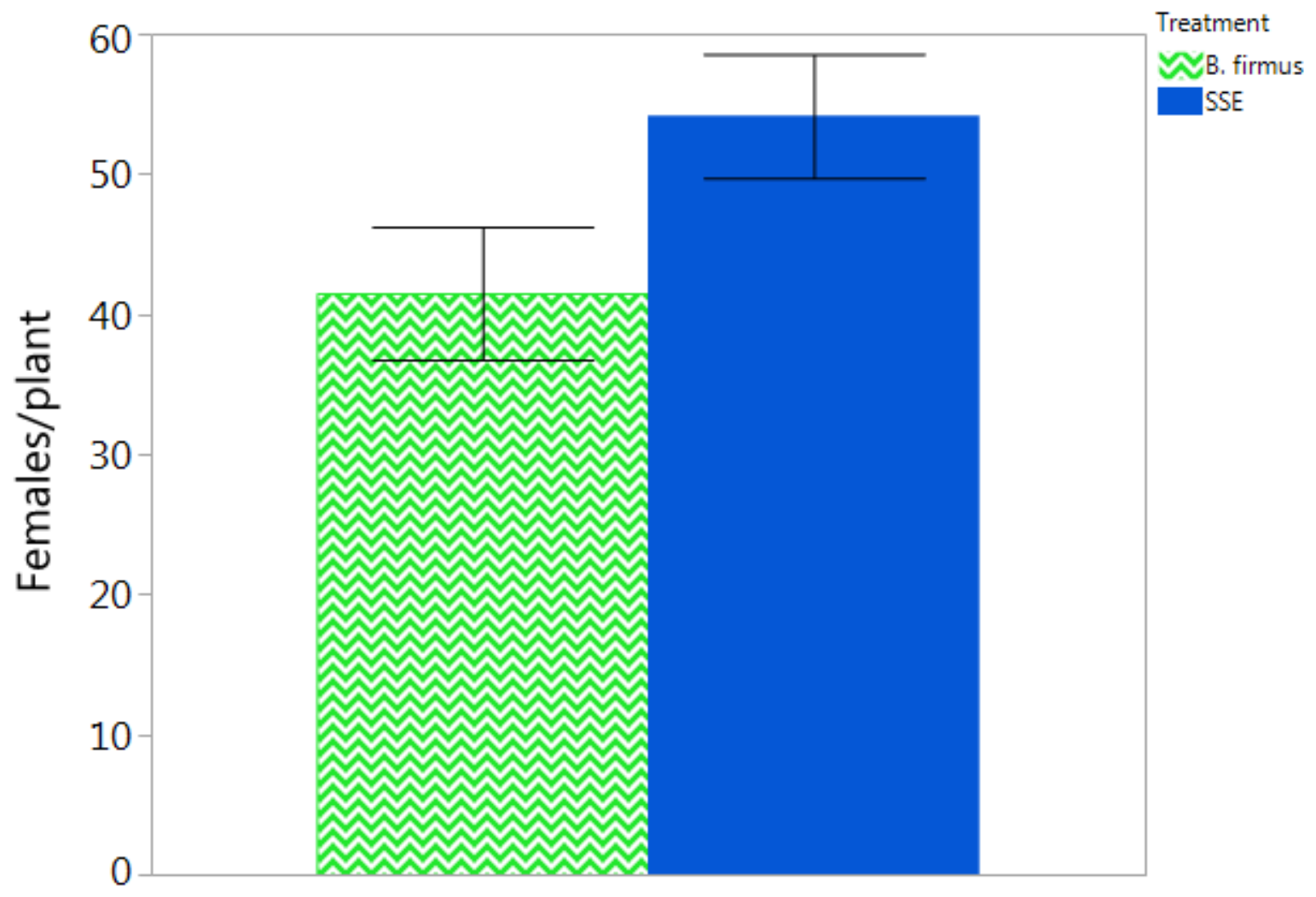

Fig. 2.8. In-sand reproduction assay (40-day): The average number of reproductive $M$. hapla females within the roots of $B$. firmus-treated tomato seedlings vs. SSE-treated tomato seedlings. Error bars represent standard error of the means. 


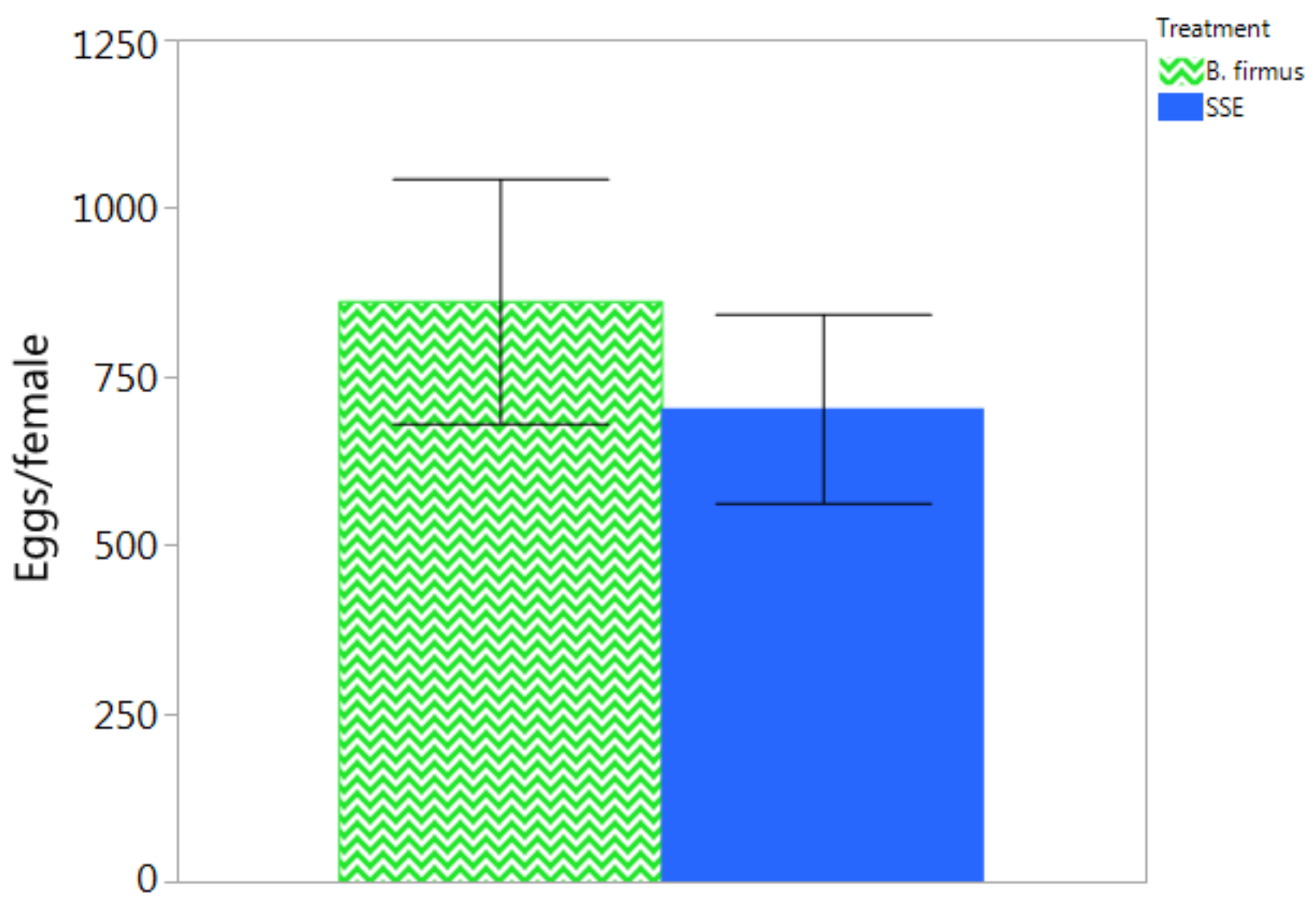

Fig. 2.9. In-sand reproduction assay (40-day): The average number of eggs per reproductive $M$. hapla female within the roots of $B$. firmus-treated tomato seedlings vs. SSE-treated tomato seedlings. Error bars represent standard error of the means. 


\section{References}

Bayer CropScience. 2016. Accessed April 25, 2016.

https://www.cropscience.bayer.us/products/seedgrowth/poncho-votivo/the-votivo-solution

Bird, A. F. 1959. The attractiveness of roots to the plant parasitic nematodes Meloidogyne javanica and M. hapla. Nematologica 4:322-335.

Byrd Jr., D. W., Kirkpatrick, T., and Barker, K. R. 1983. An improved technique for clearing and staining plant tissues for detection of nematodes. Journal of Nematology 15:142-143.

Durham, M. 2013. Characterization of root colonization by the biocontrol bacterium Bacillus firmus strain GB126. M.S. Thesis. Auburn University, Auburn, AL. 65 p.

Favery, B., Quentin, M., Jaubert-Possamai, S., and Abad, P. 2016. Gall-forming root-knot nematodes hijack key plant cellular functions to induce multinucleate and hypertrophied feeding cells. Journal of Insect Physiology 84:60-69.

Föll, R. L., Pleyers, A., Lewandovski, G. J., Wermter, C., Hegemann, V., and Paul, R. J. 1999. Anaerobiosis in the nematode Caenorhabditis elegans. Comparative Biochemistry and Physiology Part B: Biochemistry and Molecular Biology 124:269-280.

Handoo Z.A. 1998. Plant-parasitic nematodes. Accessed March 24, 2016. http://www.ars.usda.gov/Main/docs.htm?docid=9628\&pf=1\&cg_id=0

Höckelmann, C., Moens, T., and Jüttner, F. 2004. Odor compounds from cyanobacterial biofilms acting as attractants and repellents for free-living nematodes. Limnology and Oceanography 49:1809-1819.

Hussey, R.S. and Barker, K.R. 1973. A comparison of methods of collecting inocula of Meloidogyne spp., including a new technique. Plant Disease Reporter 57:1025-28.

Kloepper, J. W., Ryu, C. M., and Zhang, S. 2004. Induced systemic resistance and promotion of plant growth by Bacillus spp. Phytopathology 94:1259-1266.

Linford, B. M. 1939. Attractiveness of roots and excised shoot tissues to certain nematodes. Proceedings of the Helminthological Society of Washington 6:11-18.

Mendoza, A., Kiewnick, S., and Sikora, R. 2008. In vitro activity of Bacillus firmus against the burrowing nematode Radopholus similis, the root-knot nematode Meloidogyne incognita and the stem nematode Ditylenchus dipsaci. Biocontrol Science and Technology 18:377-389.

Neidig, N., Paul, R. J., Scheu, S., and Jousset, A. 2011. Secondary metabolites of Pseudomonas fluorescens CHA0 drive complex non-trophic interactions with bacterivorous nematodes. Microbial Ecology 61:853-859. 
Niu, Q., Huang, X., Zhang, L., Li, Y., Li, J., Yang, J., and Zhang, K. 2006. A neutral protease from Bacillus nematocida, another potential virulence factor in the infection against nematodes. Archives of Microbiology 185:439-448.

Peleg, I. and Feldman, K. 1996. Bacillus firmus CNCM I-1582 or Bacillus cereus CNCM I-1562 for controlling nematodes. U.S. Patent No. 6406690 B1. Washington, DC: U.S. Patent and Trademark Office.

Perry, R. N. 2005. An evaluation of types of attractants enabling plant-parasitic nematodes to locate plant roots. Russian Journal of Nematology 13:83-88.

Qiu, L. and Bedding, R. A. 2000. Energy metabolism and survival of the infective juveniles of Steinernema carpocapsae under oxygen-deficient conditions. Journal of Nematology 32:271280.

Reynolds, A. M., Dutta, T. K., Curtis, R. H., Powers, S. J., Gaur, H. S., and Kerry, B. R. 2011. Chemotaxis can take plant-parasitic nematodes to the source of a chemo-attractant via the shortest possible routes. Journal of the Royal Society Interface 8:568-577.

Terefe, M., Teferaera, T., and Sakhuja, P. 2009. Effect of a formulation of Bacillus firmus on root-knot nematode Meloidogyne incognita infestation and the growth of tomato plants in greenhouse and nursery. Journal of Invertebrate Pathology. 100:94-99.

Troemel, E. R., Kimmel, B. E., and Bargmann, C. I. 1997. Reprogramming chemotaxis responses: sensory neurons define olfactory preferences in C. elegans. Cell 91:161-169.

USDA. 2015. 2014 peach and apple production. Accessed March 24, 2016.

http://www.nass.usda.gov/Statistics_by_State/West_Virginia/Publications/Current_News_Releas e/annualfruit.pdf

Vos, C., Van Den Broucke, D., Lombi, F. M., De Waele, D., and Elsen, A. 2012. Mycorrhizainduced resistance in banana acts on nematode host location and penetration. Soil Biology and Biochemistry 47:60-66.

Wang, C., Bruening, G., and Williamson, V. M. 2009. Determination of preferred pH for rootknot nematode aggregation using Pluronic F-127 gel. Journal of Chemical Ecology 35:12421251.

Wei, J. Z., Hale, K., Carta, L., Platzer, E., Wong, C., Fang, S. C., and Aroian, R. V. 2003. Bacillus thuringiensis crystal proteins that target nematodes. Proceedings of the National Academy of Sciences 100:2760-2765.

Wieser, W. 1955. The attractiveness of plants to larvae of root-knot nematodes. 1. The effect of tomato seedlings and excised roots on Meloidogyne hapla Chitwood. Proceedings of the Helminthological Society of Washington 22:106-112. 
Yilmaz, M., Soran, H., and Beyatli, Y. 2006. Antimicrobial activities of some Bacillus spp. strains isolated from the soil. Microbiological Research 161:127-131.

Zhang, F., Peng, D., Ye, X., Yu, Z., Hu, Z., Ruan, L., and Sun, M. 2012. In vitro uptake of 140 $\mathrm{kDa}$ Bacillus thuringiensis nematicidal crystal proteins by the second stage juvenile of Meloidogyne hapla. PloS One 7:e38534.

Zhao, X., Schmitt, M., and Hawes, M. C. 2000. Species-dependent effects of border cell and root tip exudates on nematode behavior. Phytopathology 90:1239-1245. 


\section{CHAPTER 3}

\section{EFFICACY OF BACILLUS FIRMUS AS A BIONEMATICIDE AGAINST XIPHINEMA}

AMERICANUM

\section{Introduction}

Dagger nematodes of the genus Xiphinema are economically important plant-parasitic nematodes that cause damage to a wide range of agricultural crops worldwide. These nematodes are ectoparasites that migrate through soil, feeding on young root tips and root hairs of susceptible plants with a long, needle-like stylet. High dagger nematode populations can lead to significant yield losses and a general decline in plant health, though direct damage related to Xiphinema spp. infestation is generally not regarded as an immediate concern for growers. The economic importance of dagger nematodes is derived from their ability to transmit different nepoviruses (nematode transmitted polyhedral viruses), including tomato ringspot virus (TomRSV), tobacco ringspot virus (TRSV), and grapevine fanleaf virus (GFLV), to plants (Forer \& Stouffer, 1982; McGuire, 1964; Raski \& Hewitt, 1960).

As dagger nematodes feed on the roots of virus-infected plants, viral particles may adhere to the stylet and esophageal lumen of the nematode, initiating the potential for viral transmission to a new host plant (Taylor \& Robertson, 1970). During feeding, the dagger nematode uses its stylet to puncture the plant cell wall and secrete salivary enzymes prior to ingesting the cell's cytoplasmic contents. At this time, any retained viral particles may dislodge and infect the new host. Viral particles attached to the nematode stylet are shed with each molt but may persist within adult worms for several years (Taylor \& Raski, 1964; Demangeat et al., 2005). Without intervention, the longevity of viral retention and lengthy lifespan of dagger nematodes (2-5 years) allow for long-term spread of devastating plant diseases.

Management practices for nepoviruses include the use of resistant rootstocks and control of the nematode vector, though reducing Xiphinema spp. population sizes can prove difficult due to a wide host range and persistence in fallow soil. Combining several traditional management practices, such as fumigation and the use of cover crops, is recommended, however, these options are not suited for all agricultural situations, and government restrictions continue to limit the use of chemical nematicides. Aside from spirotetramat (Movento), which is primarily an insecticide, there are presently no registered chemical nematicides available for application on 
bearing fruit trees in the US. Pre-plant nematicides and fumigants are available but these will not provide control over the life of the orchard. In recent years, focus in nematode management has shifted to the use of ubiquitous, soil-dwelling organisms as a means of controlling plant-parasitic nematode populations. While a large portion of bionematicide research has focused on endoparasites such as Meloidogyne spp., a variety of organisms including Pasteuria penetrans, Cunninghamella elegans, Variovorax paradoxus, Pseudomonas pseudoalcaligenes, Bacillus mycoides, Bacillus sphaericus, Bacillus thuringiensis, Curtobacterium flaccumfaciens, Pseudomonas putida, Pseudomonas alcaligenes, and Pseudomonas viridiflava have been reported to decrease dagger nematode population densities and damage (Ciancio, 1995; Galper et al., 1991; Aballay et. al., 2012). Bacillus firmus, a gram-positive, endospore-forming bacterium, is the active ingredient in a nematicide currently marketed by Bayer CropScience. This organism has shown success in controlling populations of several nematode species, namely Meloidogyne spp., by direct toxicity and disruption of host-finding ability. Although dagger nematodes are listed as key pests controlled by this B. firmus product, its efficacy as a bionematicide against species of dagger nematode indigenous to West Virginia peach and apple orchards remains unclear.

Peach and apple production is a valuable industry in West Virginia and other MidAtlantic states, with a combined revenue exceeding 18 million dollars annually in West Virginia alone (USDA, 2015). These trees are highly susceptible to dagger nematodes and the spread of TomRSV, a virus that leads to development of peach stem pitting (PSP) and apple union necrosis diseases (AUND) (Georgi, 1988; Jaffee et al., 1987). The purpose of this study was to determine if the bacterium B. firmus is an effective biological control organism against the West Virginianative dagger nematode, Xiphinema americanum.

\section{Materials and methods}

Bacillus firmus

A research grade formulation containing a minimum of $1.0 \times 10^{11} \mathrm{CFU} / \mathrm{gram}$ of Bacillus firmus (I-1582) provided by Bayer CropScience was used in this study. A Bacillus isolate from this formulation (named BF1) was selected and the identity was confirmed using a range of morphological and biochemical characteristics analogous to B. firmus (Appendix 1). Later, rRNA gene analysis of the BF1 isolate resulted in 100\% identity with Bacillus cereus, Bacillus 
thuringiensis, and Bacillus anthracis and 93\% identity with Bacillus firmus (Appendix 1). For the following experiments, the isolated BF1 culture is referred to as B. firmus. It was grown in $100 \mathrm{~mL}$ of TSB at $28^{\circ} \mathrm{C}$ for 24 hours to produce a concentration of approximately $10^{7} \mathrm{CFU} / \mathrm{mL}$. The day-old culture was centrifuged at $5000 \mathrm{rpm}$ for 20 minutes to separate bacterial cells and TSB. The supernatant was removed and the B. firmus cells were re-suspended in $100 \mathrm{~mL}$ of SSE.

\section{Sterile soil extract (SSE)}

Sterile soil extract (SSE) was used as the control for all experiments in this study. SSE was used in lieu of sterile distilled water and TSB based on preliminary results that exhibited a larger nematode mortality rate for both cell-free sterile distilled water and cell-free TSB when compared to cell-free SSE. SSE was prepared by combining $1000 \mathrm{~g}$ of a Tilsit silt loam soil obtained from the West Virginia University Organic Farm in $1 \mathrm{~L}$ of tap water. The soil and water were mixed thoroughly then allowed to settle for 24 hours. The water was decanted and autoclaved twice for 90 minutes each time.

\section{Xiphinema americanum}

Dagger nematodes were collected from an orchard in Hampshire County, West Virginia with a Lehew-Berks Complex soil (channery fine sandy loam, Loamy-skeletal, siliceous, semiactive, mesic Typic Dystrudepts) and extracted using a sieving and sucrose-centrifugation

method. One hundred $\mathrm{cm}^{3}$ of soil was placed in a pitcher, mixed with tap water, and immediately poured through a $600-\mu \mathrm{m}$-pore mesh sieve to remove large debris. The water was then washed through a $38-\mu \mathrm{m}$-pore mesh sieve and anything remaining in the sieve was collected in a tube and centrifuged at $1000 \mathrm{rpm}$ for 3 minutes. The supernatant was discarded and the nematodes were re-suspended in a $60 \%$ sucrose solution. The tubes were centrifuged at $1000 \mathrm{rpm}$ for an additional 3 minutes. After centrifugation, the sucrose/nematode suspension was washed through a 25- $\mu \mathrm{m}$-pore mesh sieve to collect nematodes. Those resembling dagger nematodes of various life stages were picked from the samples and used for the following experiments. Measurements of stylet and tail lengths and anal body diameters were taken for species verification (Lamberti and Bleve-Zacheo, 1979).

Tomato seedlings 
Rutgers tomato seeds were surface disinfested by washing in a 70\% ethanol solution for 2 minutes, then a $3 \% \mathrm{NaOCl}$ solution for 10 minutes and immediately rinsing with sterile distilled water three times. Seeds were transferred to $0.75 \%$ TSA plates and incubated at $28^{\circ} \mathrm{C}$ for 5 days or until roots were approximately $2-4 \mathrm{~cm}$. Seedlings that showed signs of microbial contamination were discarded.

\section{Experiment 1. Bacillus firmus direct toxicity assay}

To determine if various concentrations of $B$. firmus are directly toxic to $X$. americanum, we tested the hypothesis that survival of $X$. americanum will be affected by the concentration of B. firmus. A $10^{7} \mathrm{CFU} / \mathrm{mL}$ concentration of $B$. firmus in SSE was serially diluted to produce seven $B$. firmus concentrations from approximately $10^{1}-10^{7} \mathrm{CFU} / \mathrm{mL}$. Bacterial concentrations were enumerated using serial dilution and spread plating. Two $\mathrm{mL}$ of each bacterial concentration were added to $35-\mathrm{mm}$ plastic dishes and uniformly spread throughout the plates. Plates with cell-free SSE were used as a control. Approximately $10 \mathrm{X}$. americanum nematodes of various life stages were added to each dish and the plates were incubated in darkness at room temperature $\left(23 \pm 2^{\circ} \mathrm{C}\right)$. Nematode mortality was determined at 24,48 , and 72 hours. Nonmotile nematodes were probed with a fine needle and those that were unresponsive after probing were considered dead. Four replications were used for each B. firmus concentration and the entire experiment was conducted three times. Data were analyzed using ANOVA and treatment means were compared with the control using a nonparametric Kruskal-Wallis test.

\section{Experiment 2. Filter paper attraction assay}

To determine if movement of dagger nematodes is affected by the presence of B. firmus, we tested the hypothesis that a smaller portion of $X$. americanum will accumulate near $B$. firmustreated filter paper compared with SSE-treated filter paper. Sterile filter paper disks $(12.7 \mathrm{~mm}$ dia) were soaked in either a $10^{7} \mathrm{CFU} / \mathrm{mL}$ concentration of $B$. firmus in SSE or cell-free SSE. Approximately $2 \mathrm{~mL}$ of a 23\% Pluronic gel medium were pipetted onto 75 X 25 -mm glass microscope slides, covering the entire surface. The slides were partitioned into three labeled sections: B. firmus $(32.5$ X $25 \mathrm{~mm})$, center $(10 \mathrm{X} 25 \mathrm{~mm})$, and SSE $(32.5$ X $25 \mathrm{~mm})$. Treated filter paper disks were immediately placed towards the edges of either the B. firmus or SSE sections of the slides, approximately $40 \mathrm{~mm}$ apart. No filter paper disks were placed in the 
centers. The slides were placed in petri dishes with a dampened paper towel and incubated at $28^{\circ} \mathrm{C}$ for 1 hour. After incubation, 10-50 X. americanum nematodes of various life stages were added to the center of each slide (Figure 3.1). The slides with nematodes were again incubated in darkness at room temperature $\left(23 \pm 2^{\circ} \mathrm{C}\right)$. The number of nematodes in each section of the slide was counted at 1,2, 4, and 24 hours post inoculation. The experiment had eight replicates.

\section{Experiment 3. Tomato seedling attraction assay}

To determine if the migration of $X$. americanum towards host plant roots is altered by the presence of $B$. firmus, we tested the hypothesis that the number of $X$. americanum that move towards $B$. firmus-treated tomato roots differs from the number of $X$. americanum that move towards SSE-treated tomato roots. The roots of surface disinfested tomato seedlings were submerged in either a $10^{7} \mathrm{CFU} / \mathrm{mL}$ concentration of B. firmus in SSE or cell-free SSE. Approximately $2 \mathrm{~mL}$ of a 23\% Pluronic gel medium were pipetted onto 75 X 25 -mm glass microscope slides, covering the entire surface. The slides were partitioned into three labeled sections: B. firmus ( $32.5 \times 25 \mathrm{~mm})$, center $(10 \times 25 \mathrm{~mm})$, and SSE (32.5 X $25 \mathrm{~mm})$. One tomato seedling from each treatment was immediately placed towards the edge of the appropriate section on the slides approximately $50 \mathrm{~mm}$ apart. No tomato seedlings were placed in the centers. The slides were placed in petri dishes with a dampened paper towel and incubated at $28^{\circ} \mathrm{C}$ for 1 hour. After incubation, 10-30 X. americanum nematodes of various life stages were added to the center of each slide and the slides were stored in darkness at room temperature $\left(23 \pm 2^{\circ} \mathrm{C}\right)$. The number of nematodes in each section of the slide was counted at $1,2,4,24$ and 48 hours. The experiment had five replicates.

\section{Data Analysis}

All data were analyzed using JMP and SAS software (JMP ${ }^{\circledR}$, Version Pro 11, SAS Institute Inc., Cary, NC, Copyright $\mathbb{C}^{2013}$; SAS ${ }^{\circledR}$, Version 9.3, SAS Institute Inc., Cary, NC, Copyright (C2002-2010). The significance criterion (alpha) for all tests was 0.05 unless otherwise indicated.

\section{Results}

Experiment 1. Bacillus firmus direct toxicity assay 
As the concentration of B. firmus increased from cell-free SSE to approximately $10^{7}$ $\mathrm{CFU} / \mathrm{mL}$, dishes became increasingly cloudy and visibility was impacted by the turbidity of the solution. Nematodes exposed to higher concentrations of B. firmus, specifically the two highest concentrations of approximately $10^{7}$ and $10^{6} \mathrm{CFU} / \mathrm{mL}$ were typically less active and required probing to verify living status more often than nematodes in cell-free SSE. Juveniles appeared to be more affected than adults, however, data were not collected for this observation. Due to a significant negatively-skewed distribution, data were analyzed using a Kruskal-Wallis test by ranks and treatment means were compared to the control using the Steel ranks test. Differences among treatments were not statistically significant at 24 or 48 hours (Figure 3.2). By 72 hours,

there was a significant increase in the number of nonmotile nematodes in the $10^{7} \mathrm{CFU} / \mathrm{mL}$ dishes compared to the control $(P=0.03)$, and the exposure to $B$. firmus resulted in an $11 \%$ decrease in the proportion of living nematodes.

\section{Experiment 2. Filter paper attraction assay}

Nematode movement from the center of each slide was observable within the first hour, though approximately $50 \%$ of the nematodes did not move from the centers throughout the entire length of the experiment. Data were analyzed using a repeated measures ANOVA with irregular spacing (due to unequally spaced time points), using spatial Gaussian covariance structure. Time was considered the covariate. Attraction assays using filter paper showed a significant treatment effect over time. At hours 1, 4, and 24 there were significantly more nematodes on the $B$. firmus end of the slides $(P=0.02, P=0.01, P=0.01)$ respectively. By hour $24,59 \%$ of motile nematodes were observed on the B. firmus side compared with $41 \%$ on SSE (Figure 3.3).

Experiment 3. Tomato seedling attraction assay

Data were analyzed using a repeated measures ANOVA with irregular spacing (due to unequally spaced time points), using spatial Gaussian covariance structure. Time was considered the covariate. No significant differences in the number of dagger nematodes at each treatment were seen throughout the length of this experiment, with the exception of hour $2(P=0.04)$, when $70 \%$ of motile nematodes were observed on the $B$. firmus end of slides compared to $30 \%$ of motile nematodes on SSE (Figure 3.4).

\section{Discussion}


The results of this study indicate that $B$. firmus may not be a suitable candidate for the biological control of the dagger nematode Xiphinema americanum. Exposure to a $B$. firmus concentration of $10^{7} \mathrm{CFU} / \mathrm{mL}$, the highest concentration used in this study, showed a significant decrease in the number of living nematodes by 72 hours, suggesting the production of lethal secondary metabolites. Species of Bacillus are well-known for their production of secondary metabolites that have an array of properties and functions, including those with nematicidal activities. Castaneda-Alarez et al. (2015) demonstrated that cultural filtrates of B. thuringiensis, B. megaterium, and B. amyloliquefaciens are capable of killing 54-100\% of Xiphinema index after 72 hours of exposure. Metabolite and enzyme analysis showed that these Bacillus species produce collagenases, proteases and lipases, which may play a role in their nematicidal activity. Ramezani Moghaddam et al. (2014) showed that culture filtrates of B. cereus and B. pumilus reduced egg hatch and resulted in 72-99\% juvenile mortality of Meloidogyne javanica after 48 hours of exposure. The patent submitted for the use of $B$. firmus as a bionematicide asserted that “...proteolytic and collagenolytic activities play an important role in control of nematodes..." (Patent US6406690) (Peleg \& Feldman, 1996). Mendoza et al. (2009) showed that 100\% concentrations of cell-free B. firmus culture filtrates caused $33 \%$ mortality of Meloidogyne incognita after 24 hours.

The $11 \%$ mortality of $X$. americanum seen in the present study may be explained by the production of secondary metabolites, though this degree of nematode death was only observed after exposure to the highest concentration of $B$. firmus $\left(10^{7} \mathrm{CFU} / \mathrm{mL}\right)$. Durham (2013) showed that a rifampicin-resistant $B$. firmus mutant could maintain population densities of $10^{5}, 10^{7}$, and $10^{6} \mathrm{CFU} / \mathrm{g}$ of root in the rhizosphere of corn, cotton, and soybean, respectively, 6 weeks after planting, while population densities of the rhizoplane were measured at $10^{6} \mathrm{CFU} / \mathrm{g}$ of root for each plant host. Those data suggest that $B$. firmus may be unable to maintain population densities that reflect the highest concentration used in the present study. Furthermore, since the lethal properties of $B$. firmus were observed only when the bacterial concentration reached $10^{7}$ $\mathrm{CFU} / \mathrm{mL}$, the potency of any secondary metabolites produced may be limited. These compounds would likely be diluted within the rhizosphere and have little effect on nematode populations in realistic orchard settings. However, if the metabolites suppress nematode movement, the nematode may be induced to remain near the source of the metabolite long enough for toxic effects to occur. 
An additional explanation for the significant nematode mortality observed in the present study is that high concentrations of bacteria can lead to a decrease in available oxygen over time. In the direct toxicity experiment, the increase of B. firmus concentrations from 0 in SSE to $10^{7}$ $\mathrm{CFU} / \mathrm{mL}$ was reflected in the turbidity of the solution within each plate. Thick films of bacteria were clearly visible within plates containing high bacterial concentrations. Metabolic activity of high concentrations of bacteria can deplete oxygen levels and create hypoxic and anoxic conditions. As aerobic organisms that rely solely on the diffusion of oxygen from the ambient environment, nematodes can be negatively impacted by oxygen depletion. Kung et al. (1990) demonstrated that mortality rates of Steinernema carpocapsae and S. glaseri increase over time as oxygen levels are decreased from $20-1 \%$, while Föll et al. (1999) showed that more than $80 \%$ of Caenorhabditis elegans die after 72 hours in anoxic conditions. Future studies could utilize an additional treatment of cell-free culture filtrates to confirm the presence of toxic secondary metabolites, as well as supply a steady flow of oxygen to plates to ensure oxygen depletion does not occur.

In-vitro attraction assays comparing $X$. americanum movement on Pluronic gel in the presence of $B$. firmus and cell-free SSE on filter paper showed a significant treatment effect over time. Interestingly, nematodes were observed more often on the $B$. firmus end of slides compared to the SSE control, a contrast to attraction assays observing Meloidogyne hapla movement in the presence of B. firmus as discussed in Chapter 2. Chemotaxis is a key component of nematode behavior, where various chemical gradients signal the presence of food, potential mates, and environmental stressors, prompting nematode movement (Linford, 1939; Wieser, 1955; Bird, 1959; Simon \& Sternberg, 2002; Saeki et al., 2001). Bayer CropScience reports that their $B$. firmus product, VOTiVO, “...creates a living barrier that grows with the roots to extend protection through multiple generations of nematodes..." by interfering with the nematode's ability to find host plant roots. The behavior of $X$. americanum towards $B$. firmus on filter paper observed in the present study, however, indicates the involvement of a chemoattractant produced by $B$. firmus. Because nematodes remained motile and free to migrate within the Pluronic gel throughout the length of the experiment, nematode accumulation at $B$. firmus is more likely a result of the continual lure of attractive compound(s) produced by B. firmus rather than the presence of chemicals affecting nematode motility. In this case, the addition of $B$. firmus to roots may lead to an accumulation of dagger nematodes near the source of the attractant, though it 
remains unclear whether this interaction would result in a higher or lower degree of nematode parasitism. Aballay et al. (2012) showed that treatment of grapevines with various rhizobacteria including B. mycoides, B. sphaericus, and B. thuringiensis significantly reduced feeding damage by $X$. index compared with the untreated control.

Attraction assays utilizing $B$. firmus- and SSE-treated tomato seedlings showed no significant treatment effect, with the exception of hour two, when more nematodes were observed on the $B$. firmus portion of slides. Again, these data conflict with the behavior of $M$. hapla towards $B$. firmus-treated tomato seedlings observed in the tomato seedling attraction assay discussed in Chapter 2. The lack of significant treatment effect may be explained by small nematode sample sizes and the use of an unsuitable host plant. In the present study, 10-30X. americanum nematodes of various life stages were placed on each slide. Throughout the length of the experiment, a relatively large portion of these nematodes remained motionless in the centers. Larger sample sizes may have compensated for this lack of nematode movement and generated more significant results. Tomato seedlings were chosen for use in attraction assays based on their ease and speed of germination, however, the parasitic association of Xiphinema spp. with tomato is not as strong as with other crops. Offering a more suitable host, such as corn, may have initiated a more notable nematode response (Batchelor, 1993).

The present study presents evidence of the limited potential of $B$. firmus as a bionematicide for the control of $X$. americanum. In-vitro experiments demonstrated that, although B. firmus may produce lethal secondary metabolites, these metabolites have low nematicidal activity. Additionally, the production of a chemoattractant may result in the accumulation of nematodes at host plant roots.

The observed difference in behavior of $X$. americanum seen in the present study and $M$. hapla as discussed in Chapter 2 in the presence of B. firmus is an interesting outcome that suggests that the effect of any chemotactic factor produced by B. firmus is species-specific. This contrasting behavior between nematode species is an indication that maximum nematode control may only be achieved by treating infested soils with a combination of antagonistic organisms. Mendoza \& Sikora (2009) showed this trend by combining applications of a nonpathogenic strain of Fusarium oxysporum (considered to induce resistance within banana plants), and $B$. firmus to soils inoculated with the endoparasitic nematode, Radopholus similis. The combined 
treatments reduced $R$. similis densities between 77 and $86 \%$ compared to a reduction between 33 and $43 \%$ seen with treatments of $F$. oxysporum alone.

While this study gave insight into the interaction of X. americanum and B. firmus in a highly controlled setting, little is known about how these interactions translate to the complex orchard environment. Additional attraction assays incorporating more suitable host plants, preferably peach and apple, and increasing dagger nematode sample sizes would allow for a more accurate interpretation of this B. firmus/dagger nematode relationship. The present study was useful in facilitating a better understanding of the nematicidal mode of action of $B$. firmus but, ultimately, long-term nematicide trials within orchards, utilizing applications of $B$. firmus throughout several growing seasons should be the future direction of $B$. firmus efficacy trials. Monitoring $X$. americanum populations, damage, and viral transmission over time would give the most meaningful assessment of $B$. firmus as a bionematicide against $X$. americanum. 


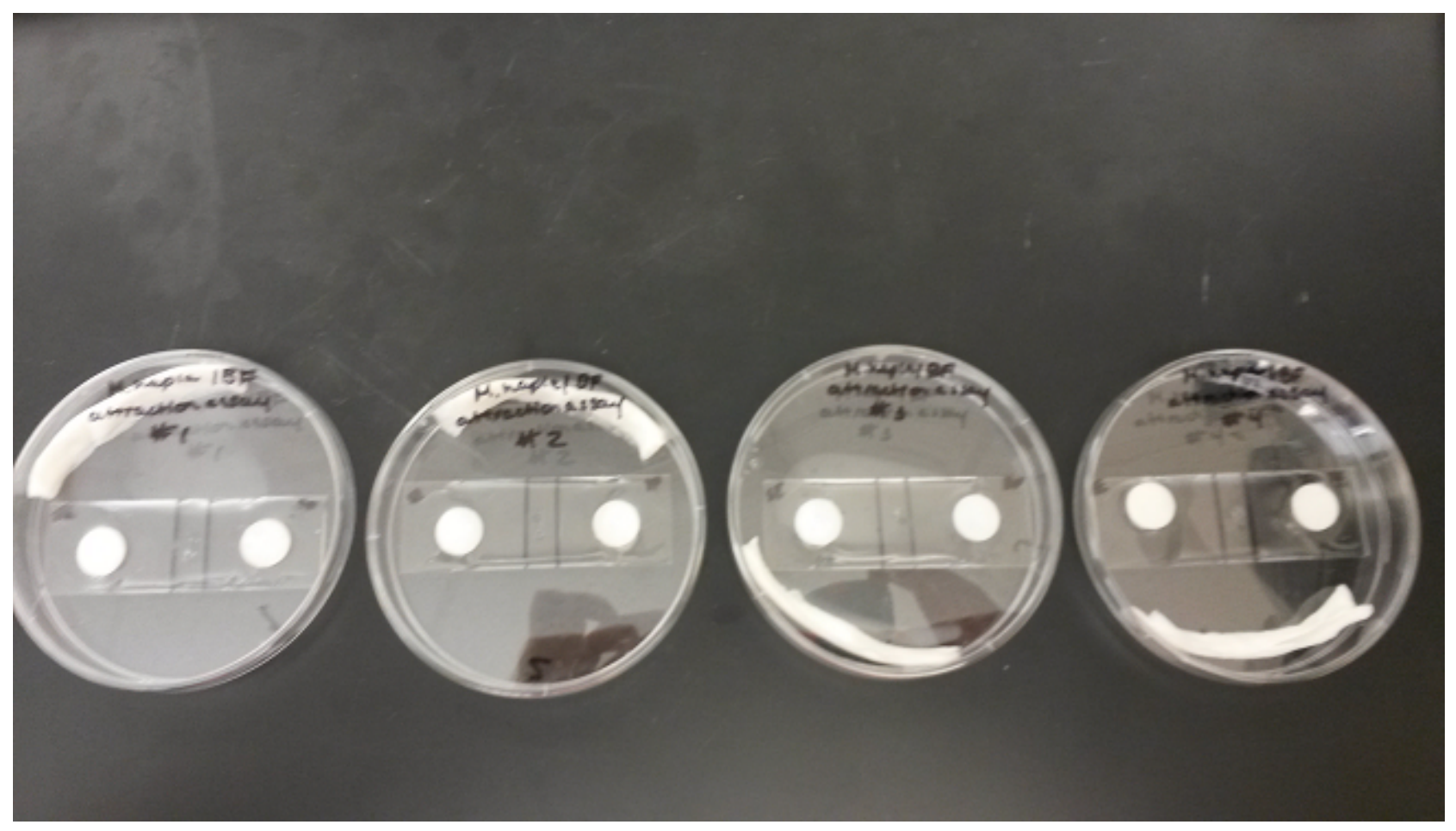

Fig. 3.1. In-vitro attraction assay set-up: B. firmus and SSE treated filter paper on opposite ends of slides covered in Pluronic gel. 


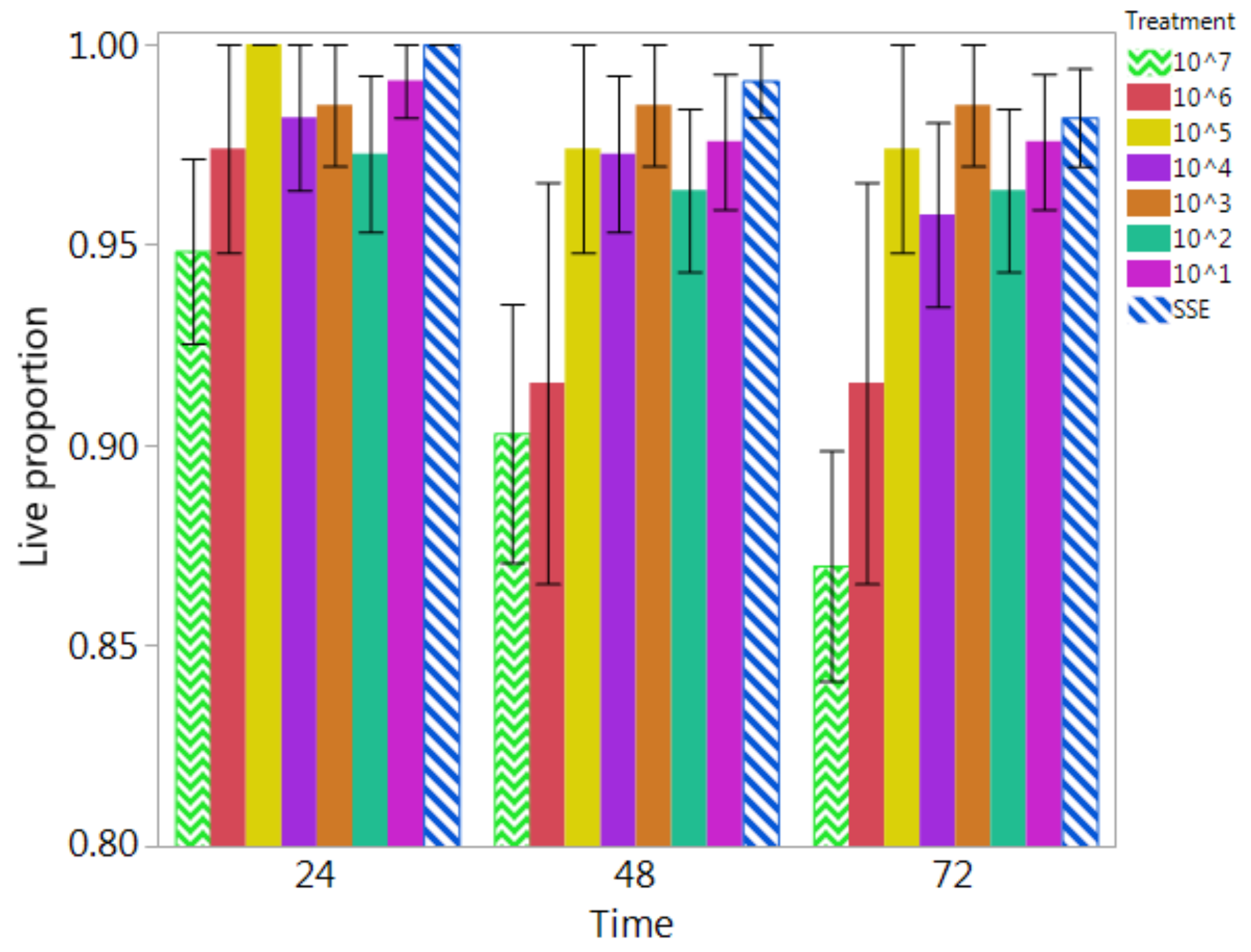

Fig. 3.2. Direct toxicity assay: Proportion of living $X$. americanum nematodes after 24,48 , and 72 hours of exposure to different concentrations of B. firmus. Error bars represent standard error of the mean. 


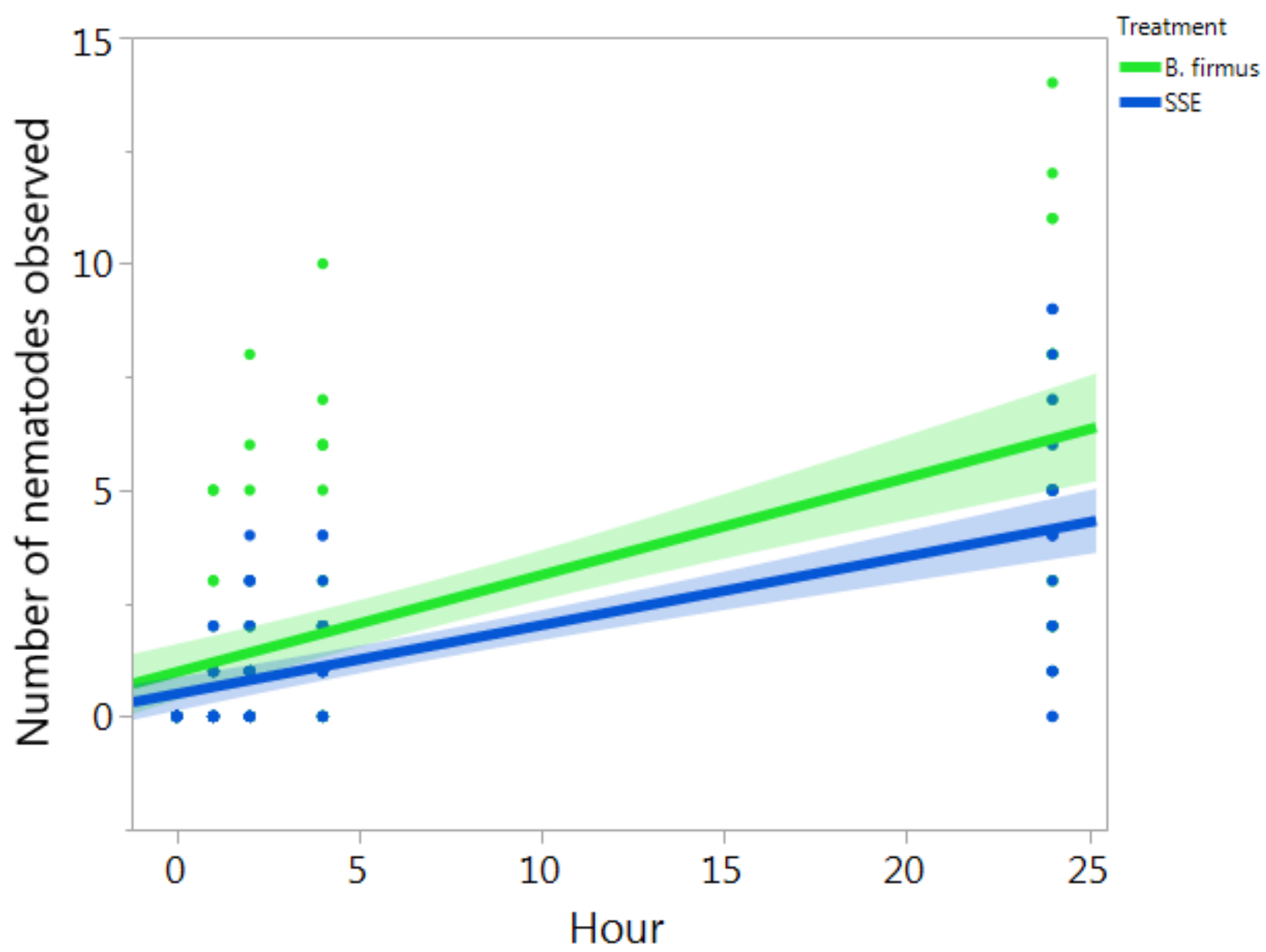

Fig. 3.3. Filter paper attraction assay: Number of $X$. americanum nematodes observed on the $B$. firmus portion of the slide vs. the SSE portion of the slide over time. The shaded regions represent confidence intervals of the slope. 


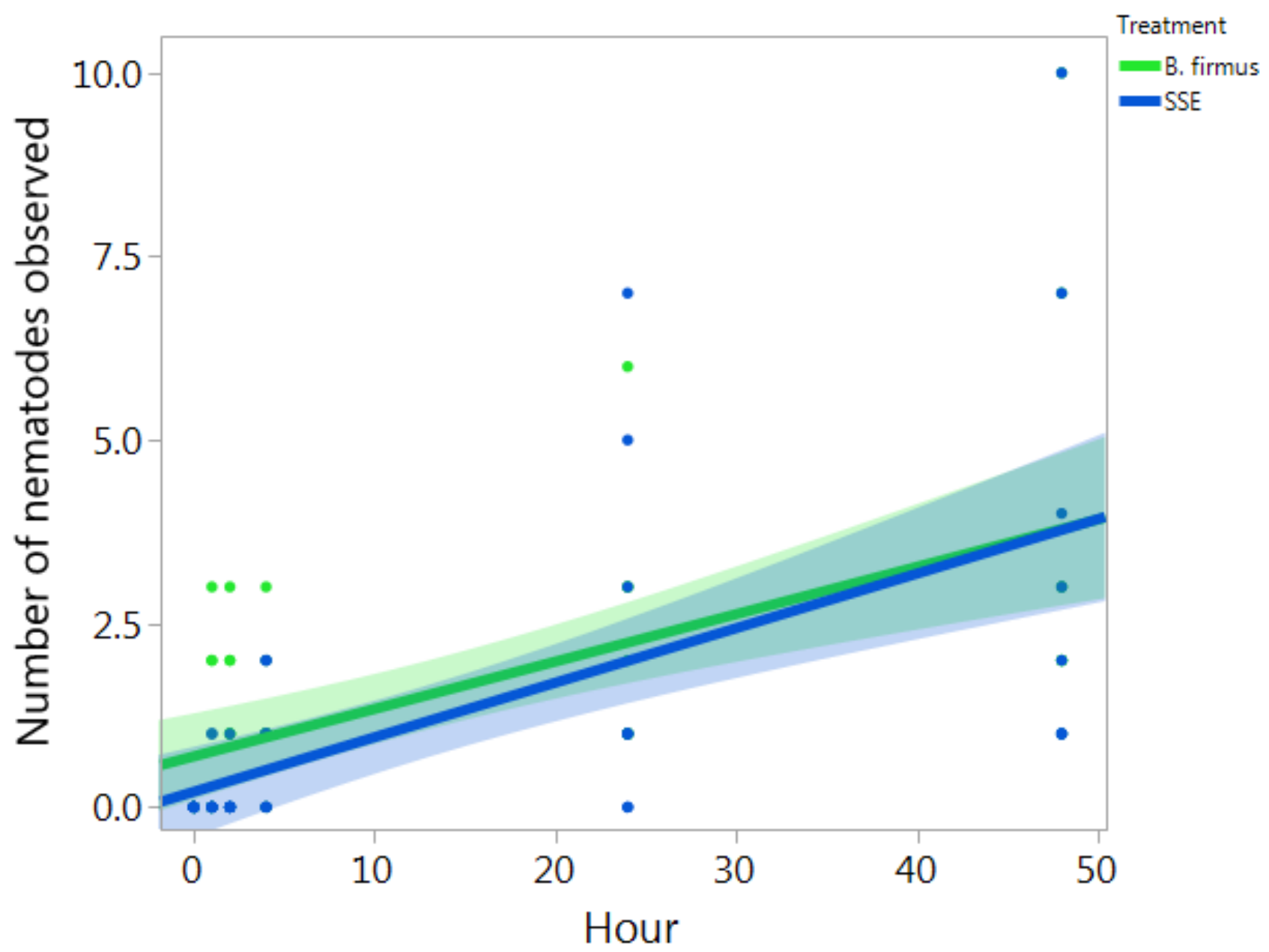

Fig. 3.4. Tomato seedling attraction assay: Number of $X$. americanum nematodes observed on the $B$. firmus portion of the slide vs. the SSE portion of the slide over time The shaded regions represent confidence intervals of the slope. 


\section{REFERENCES}

Aballay, E., Prodan, S., Mårtensson, A., and Persson, P. 2012. Assessment of rhizobacteria from grapevine for their suppressive effect on the parasitic nematode Xiphinema index. Crop Protection 42:36-41.

Bayer CropScience. 2016. Accessed April 25, 2016.

https://www.cropscience.bayer.us/products/seedgrowth/poncho-votivo/the-votivo-solution

Batchelor, T. 1993. Population dynamics of dagger nematode: Influences of rotation crops. M. S. Thesis, West Virginia University, Morgantown, WV. 33 p.

Bird, A. F. 1959. The attractiveness of roots to the plant parasitic nematodes Meloidogyne javanica and M. hapla. Nematologica 4:322-335.

Castaneda-Alvarez, C., Prodan, S., Rosales, I. M., and Aballay, E. 2015. Exoenzymes and metabolites related to the nematicidal effect of rhizobacteria on Xiphinema index Thorne \& Allen. Journal of Applied Microbiology 120:413-424.

Ciancio, A. 1995. Density-dependent parasitism of Xiphinema diversicaudatum by Pasteuria penetrans in a naturally infested field. Phytopathology 85:144-149.

Demangeat, G., Voisin, R., Minot, J. C., Bosselut, N., Fuchs, M., and Esmenjaud, D. 2005. Survival of Xiphinema index in vineyard soil and retention of Grapevine fanleaf virus over extended time in the absence of host plants. Phytopathology 95:1151-1156.

Durham, M. 2013. Characterization of root colonization by the biocontrol bacterium Bacillus firmus strain GB126. M.S. Thesis. Auburn University, Auburn, AL. 65 p.

Föll, R. L., Pleyers, A., Lewandovski, G. J., Wermter, C., Hegemann, V., and Paul, R. J. 1999. Anaerobiosis in the nematode Caenorhabditis elegans. Comparative Biochemistry and Physiology Part B: Biochemistry and Molecular Biology 124:269-280.

Forer, L. B., and Stouffer, R. F. 1982. Xiphinema spp. associated with tomato ringspot virus infection of Pennsylvania fruit crops. Plant Disease 66:735-736.

Galper, S., Cohn, E., Spiegel, Y., and Chet, I. 1991. A collagenolytic fungus, Cunninghamella elegans, for biological control of plant-parasitic nematodes. Journal of Nematology, 23:269-274.

Georgi, L. L. 1988. Transmission of tomato ringspot virus by Xiphinema americanum and X. rivesi from New York apple orchards. Journal of Nematology 20:304-308.

Hewitt, W.B., Raski, D. J., Goheen, A. C. 1958. Nematode vector of soil-borne fanleaf virus of grapevines. Phytopathology 48:586-595. 
Jaffee, B. A., Harrison, M. B., Shaffer, R. L., and Strang, M. B. 1987. Seasonal population fluctuation of Xiphinema americanum and X. rivesi in New York and Pennsylvania orchards. Journal of Nematology 19:369-378.

Kung, S.-P., Gaugler, R., and Kaya, H. K. 1990. Influence of soil pH and oxygen on persistence of Steinernema spp. Journal of Nematology 22:440-445.

Lamberti, F., Bleve-Zacheo, T. 1979. Studies on Xiphinema americanum sensu lato with descriptions of fifteen new species (Nematoda, Longidoridae). Nematologia Mediterranea 7:51106.

Linford, B. M. 1939. Attractiveness of roots and excised shoot tissues to certain nematodes. Proceedings of the Helminthological Society of Washington 6:11-18.

McGuire, J. M. 1964. Efficiency of Xiphinema americanum as a vector of tobacco ringspot virus. Phytopathology 54:799-801.

Mendoza, A. R. and Sikora, R. A. 2009. Biological control of Radopholus similis in banana by combined application of the mutualistic endophyte Fusarium oxysporum strain 162, the egg pathogen Paecilomyces lilacinus strain 251 and the antagonistic bacteria Bacillus firmus. BioControl 54:263-272.

Peleg, I. and Feldman, K. 1996. Bacillus firmus CNCM I-1582 or Bacillus cereus CNCM I-1562 for controlling nematodes. U.S. Patent No. 6406690 B1. Washington, DC: U.S. Patent and Trademark Office.

Ramezani Moghaddam, M., Mahdikhani Moghaddam, E., Baghaee Ravari, S., and Rouhani, H. 2014. The nematicidal potential of local Bacillus species against the root-knot nematode infecting greenhouse tomatoes. Biocontrol Science and Technology 24:279-290.

Raski, D. J. and Hewitt, W. B. 1960. Experiments with Xiphinema index as a vector of fanleaf of grapevines. Nematologica 5:166-170.

Saeki, S., Yamamoto, M., and Iino, Y. U. I. C. H. I. 2001. Plasticity of chemotaxis revealed by paired presentation of a chemoattractant and starvation in the nematode Caenorhabditis elegans. Journal of Experimental Biology 204:1757-1764.

Simon, J. M. and Sternberg, P. W. 2002. Evidence of a mate-finding cue in the hermaphrodite nematode Caenorhabditis elegans. Proceedings of the National Academy of Sciences 99:15981603.

Taylor, C. E. and Raski, D. J. 1964. On the transmission of grape fanleaf by Xiphinema index. Nematologica 10:489-495. 
Taylor, C. E. and Robertson, W. M. 1970. Sites of virus retention in the alimentary tract of the nematode vectors, Xiphinema diversicaudatum (Micol.) and X. index (Thorne and Allen). Annals of Applied Biology 66:375-380.

USDA. 2015. 2014 peach and apple production. Accessed March 24, 2016.

http://www.nass.usda.gov/Statistics_by_State/West_Virginia/Publications/Current_News_Releas e/annualfruit.pdf

Wieser, W. 1955. The attractiveness of plants to larvae of root-knot nematodes. The effect of tomato seedlings and excised roots on Meloidogyne hapla Chitwood. Proceedings of the Helminthological Society of Washington 22:106-112. 


\section{Appendix 1}

\section{Bacillus firmus isolation 1}

A research grade formulation containing a minimum of $1.0 \times 10^{11} \mathrm{CFU} / \mathrm{gram}$ of Bacillus firmus (I-1582) provided by Bayer CropScience was used to obtain the B. firmus isolate that was used in the studies described in this thesis. One gram of the product was placed into a flask containing $100 \mathrm{~mL}$ of TSB and incubated at $28^{\circ} \mathrm{C}$ for 24 hours. The culture was then used to streak TSA plates for isolation. Plates were incubated at $28^{\circ} \mathrm{C}$ for 24 hours. Following incubation, one main morphological type of colony (Morphotype 1) could be seen covering approximately $80-90 \%$ of each plate and a secondary morphological type (Morphotype 2) covered approximately $10-20 \%$ of each plate. Morphotype 1 colonies had a glossy cream-yellow coloring with entire-slightly irregular margins. Colony sizes averaged 3-5 mm after 24 hours of growth. Morphotype 2 colonies were transparent-cream colored and circular with entire margins. Colony sizes averages 1-2 mm after 24 hours of growth. Several colonies of both morphological types were chosen for staining and biochemical testing.

Gram stains showed gram-positive bacillus-shaped cells, 3-5 $\mu \mathrm{m}$ X 1.5-2 $\mu \mathrm{m}$ for both morphotypes. Spore stains showed one slightly offset endospore per vegetative cell. Both morphotypes displayed similar results for biochemical tests. Positive results included catalase production, reduction of nitrate to nitrite, starch hydrolysis, casein and gelatin decomposition, and production of acid in glucose and mannitol. Negative tests included oxidase, production of acid in lactose, urease, indole, citrate, and Voges-Proskauer. Based on morphology and biochemical testing, a Morphotype 1 isolate (BF1) was chosen to be used for the experiments described in this thesis.

\section{rRNA gene analysis 1}

Following the studies described in this thesis, 16S rRNA gene sequencing was performed on the BF1 isolate to verify the presence of Bacillus firmus. DNA was extracted from cells and universal 16S rRNA bacterial primers Bakt_341F 5'-CCTACGGGNGGCWGCAG-3' and Bakt805R 5'-GACTACHVGGGTATCTAATCC-3' were used to amplify a $~ 450 \mathrm{bp}$ portion of the gene. PCR products were visualized on a 1\% agarose gel under UV light to confirm the presence of a $\sim 450 \mathrm{bp}$ band. Sanger sequences were generated by Eurofins MWG Operon LLC in Louisville, KY. Blasting Sanger sequences in the National Center for Biotechnology Information 
(NCBI) database resulted in 100\% identity with Bacillus cereus, B. thuringiensis, and B. anthracis and $93 \%$ identity with $B$. firmus. These results lead to re-isolation from the original Bacillus firmus product provided by Bayer CropScience and additional rRNA gene sequencing.

\section{Bacillus firmus isolation 2}

The research grade formulation of Bacillus firmus (I-1582) provided by Bayer CropScience as previously mentioned in "Bacillus firmus isolation 1" was used to re-isolate Bacillus firmus for species verification. One gram of the product was placed into a flask containing $100 \mathrm{~mL}$ of TSB and incubated at $28^{\circ} \mathrm{C}$ for 24 hours. The culture was then used to streak TSA plates for isolation. Plates were incubated at $28^{\circ} \mathrm{C}$ for 24 hours. Again, following incubation, one main morphological type of colony (Morphotype 1) could be seen covering approximately $80-90 \%$ of each plate and a secondary morphological type (Morphotype 2) covered approximately $10-20 \%$ of each plate. Morphotype 1 colonies had a glossy cream-yellow coloring with entire-slightly irregular margins. Colony sizes averaged 3-5 mm after 24 hours of growth. Morphotype 2 colonies were transparent-cream colored and circular with entire margins. Colony sizes averages 1-2 mm after 24 hours of growth. Six colonies of Morphotype 1 (BF 2-7) and three colonies of Morphotype 2 (BF 8-10) were chosen for staining and biochemical testing.

Gram stains showed gram-positive bacillus-shaped cells, 3-5 $\mu \mathrm{m}$ X 1.5-2 $\mu \mathrm{m}$ for both morphotypes. Spore stains showed one slightly offset endospore per vegetative cell. Both morphotypes displayed similar results for biochemical tests. Positive results included catalase production, reduction of nitrate to nitrite, starch hydrolysis, casein and gelatin decomposition, and production of acid in glucose. Negative tests included oxidase, production of acid in lactose, urease, indole, citrate, and Voges-Proskauer. Isolates BF3, 9, and 10 tested positive for production of acid in mannitol.

rRNA gene analysis 2

16S rRNA gene sequencing was performed on the BF1-10 isolates to verify the presence of $B$. firmus. DNA was extracted from cells and universal $16 \mathrm{~S}$ rRNA bacterial primers Bakt_341F 5'-CCTACGGGNGGCWGCAG-3' and Bakt805R 5'GACTACHVGGGTATCTAATCC-3' were used to amplify a $\sim 450 \mathrm{bp}$ portion of the gene. PCR products were visualized on a $1 \%$ agarose gel under UV light to confirm the presence of a 
$\sim 450 \mathrm{bp}$ band. Sanger sequences were generated by Eurofins MWG Operon LLC in Louisville, KY. Blasting BF1-2 sequences in the NCBI database resulted in 100\% identity with Bacillus cereus, B. thuringiensis, and B. anthracis; BF4-7 resulted in 99\% identity with B. cereus, B. thuringiensis, and B. anthracis; BF3 resulted in 100\% identity with Lysinibacillus; BF9 resulted in $100 \%$ identity with Bacillus firmus; and BF10 was unidentifiable. 